\title{
New information on the postcranial skeleton of Gracilisuchus stipanicicorum (Archosauria: Suchia) and reappraisal of its phylogenetic position
}

\author{
AGUSTINA LECUONA ${ }^{1 *}$, JULIA B. DESOJO ${ }^{2}$ and DIEGO POL ${ }^{1}$ \\ ${ }^{1}$ Museo Paleontológico Egidio Feruglio, Av. Fontana 140, U9100GYO, Trelew, Chubut, Argentina \\ ${ }^{2}$ Sección Paleontología Vertebrados, Museo Argentino de Ciencias Naturales 'Bernardino Rivadavia', \\ Av. Ángel Gallardo 470, C1405DRJ, Buenos Aires, Argentina
}

Received 16 June 2015; revised 13 January 2017; accepted for publication 1 February 2017

\begin{abstract}
Gracilisuchus stipanicicorum Romer, 1972a, the only species in its genus, is a small basal suchian, recovered from the Middle-Late Triassic Chañares Formation (La Rioja, Argentina). This species has been interpreted as related to various taxa within Archosauria, including Ornithosuchidae, Rauisuchidae and Crocodylomorpha. Recent phylogenetic analyses are concordant in recovering it in a basal position within Suchia, and the most recent analysis recovered it within the clade Gracilisuchidae. Six specimens of G. stipanicicorum are known and all of them were studied and included in a phylogenetic analysis of Archosauriformes. Re-examination of the specimens allowed us to improve the diagnosis, identify new diagnostic characters (e.g. first sacral rib with a slight distal expansion relative to the proximal portion) and, in particular, redescribe the postcranial skeleton. The phylogenetic data matrix is an updated version of a previous study with the inclusion of additional characters and taxa. The strict consensus supports the most recent phylogenetic results, recovering Gracilisuchus as a basal suchian within Gracilisuchidae. The results of this analysis resolve some important polytomies and yield higher support values than recent analyses. All previous alternative hypotheses on the affinities of Gracilisuchus were found to be highly suboptimal for the new data matrix.
\end{abstract}

ADDITIONAL KEYWORDS: Argentina - Chañares - Gracilisuchidae - postcranium - phylogeny - Pseudosuchia - systematics - Triassic.

\section{INTRODUCTION}

The Middle-Late Triassic Chañares Formation, located in the Ischigualasto - Villa Unión Basin (north-west Argentina), has yielded a very rich fossil tetrapod fauna, discovered by Dr A. S. Romer and his team from the Museum of Comparative Zoology, Harvard University (MCZ). An agreement between the MCZ and the Museum of La Plata, Argentina (MLP), made possible a 4-month-long (1964-1965) field trip to Permian and Triassic outcrops in Argentina (Romer, 1966, 1967). After two fruitless months, they began explorations near the Chañares and Gualo Rivers, where a large number of exceptionally well-preserved fossil vertebrates started to appear (Romer, 1967). This rich locality at the Chañares Formation (Romer, 1966; Romer \& Jensen, 1966) holds significance in providing

*Corresponding author. E-mail: alecuona@mef.org.ar the oldest records of many major tetrapod groups that subsequently dominated terrestrial faunas during the Mesozoic. This tetrapod assemblage includes therapsids, such as the dicynodont Dinodontosaurus sp. Tupi-Caldas, 1936, the traversodontid cynodont Massetognathus pascuali Romer, 1967b and the chiniquodontid cynodont Probelesodon minor Romer, 1973; an undetermined archosauromorph rynchosaurid (Ezcurra et al., 2013); non-archosaurian archosauriforms, namely Tropidosuchus romeri Arcucci, 1990, Gualosuchus reigi Romer, 1971a, Chanaresuchus bonapartei Romer, 1971a and Rhadinosuchus sp. von Huene, 1938 (Trotteyn et al., 2014); basal dinosauromorphs, such as Lagerpeton chanarensis Romer, 1971b (Sereno \& Arcucci, 1993), Marasuchus lilloensis (Romer, 1972c) (Sereno \& Arcucci, 1994) and Lewisuchus admixtus Romer, 1972b (= Pseudolagosuchus major Arcucci, 1987; Nesbitt et al., 2010; Novas et al., 2015); and only two suchian archosaurs, the 'rauisuchian' 
Luperosuchus fractus Romer, 1971c (Desojo \& Arcucci, 2009) and the basal suchian Gracilisuchus stipanicicorum Romer, 1972a.

The remains of the monospecific genus Gracilisuchus unearthed during Romer's expedition consist of four specimens; the designated holotype was left in the Museum of La Plata but later returned to the official repository, the Museum of the National University of La Rioja as PULR 08; the remaining three specimens were carried to the MCZ, accessioned as MCZ 4116, MCZ 4117 and MCZ 4118. Between 1970 and 1972, José Bonaparte from the Miguel Lillo Institute, Tucumán (PVL), conducted field trips to the same locality and collected a huge amount of fossil material, including two additional G. stipanicicorum specimens (PVL 4597, PVL 4612). In the original publication of this species (Romer, 1972a), G. stipanicicorum was proposed to be closely related to Ornithosuchus longidens (Huxley, 1877) within the enigmatic archosaurian group Ornithosuchidae (sensu Bonaparte, 1975a), a taxon with the unique 'crocodile-reversed' crurotarsal articulation (Chatterjee, 1978; Brinkman, 1981; Sereno, 1991) and at the time considered part of the avian line of archosaurs (Benton \& Clark, 1988). That interpretation was followed by Bonaparte (1975a), who placed Gracilisuchus in an ancestral position among ornithosuchids, but since then no agreement has been reached on its phylogenetic relationships. Later, Brinkman (1981) revised part of the material, focused on the cranium (MCZ 4117) and tarsus (PVL 4597), and reassigned Gracilisuchus to the crocodilian lineage of archosaurs. Brinkman's hypothesis was supported by several subsequent phylogenetic analyses (Benton \& Clark, 1988; Sereno \& Arcucci, 1990; Sereno, 1991; Parrish, 1993; Benton \& Walker, 2002; Benton, 2004; Li et al., 2006; Brusatte et al., 2010; Nesbitt, 2011; Butler et al., 2014), but with Gracilisuchus recovered in a variety of positions within that lineage. Benton's (1988 in Benton \& Clark, 1988) analysis found Gracilisuchus as the basalmost suchian, being the sister taxon of Crocodylomorpha + Pseudosuchia (sensu Benton \& Clark, 1988; Supporting Information, Fig. S1A), but Benton considered this a tentative result due to the lack of conclusive information for some specimens. Sereno \& Arcucci (1990) studied in detail the proximal tarsal morphology of Archosauriformes and conducted a phylogenetic analysis with mostly pelvic girdle and hind limb characters, including the tarsus (twothirds of the total characters). Based on their results, Sereno \& Arcucci (1990) proposed, for the first time, that ornithosuchids should be placed within the crocodilian lineage, Crurotarsi (sensu Sereno \& Arcucci, 1990), and considered Gracilisuchus to also be a member of this clade (Fig. S1B). Sereno (1991) expanded the phylogenetic analysis of Sereno \& Arcucci (1990) and defined the clade Suchia using G. stipanicicorum, although this species was not included in the taxon sampling of the phylogenetic analysis. Subsequently, two analyses resolved Gracilisuchus as the sister taxon to Paracrocodylomorpha (Poposauridae + Crocodylomorpha) (Parrish, 1993; Fig. S1C) and as the sister taxon to Postosuchus Chatterjee, 1985, these two taxa together being the sister group to Crocodylomorpha (Juul, 1994; Fig. S1D). Those two analyses sampled archosauriforms extensively but relied mostly on previous literature, as well as direct observation of relevant specimens. Subsequently, Benton \& Walker (2002) restudied the basal archosauriform Erpetosuchus granti Newton, 1894 and recovered this species as the sister taxon of Crocodylomorpha, with Gracilisuchus lying outside this group in a polytomy with Ornithosuchus, some 'rauisuchians' and crownward taxa (50\% majority rule consensus tree; Fig. S1E). Benton (2004) included Gracilisuchus in his large phylogenetic analysis, considering it a priori as a 'rauisuchian' (Benton, 2004: 11), but the Adams consensus showed it as the sister taxon to Phytosauridae (Fig. S1F). That same relationship was recovered by $\mathrm{Li}$ et al. (2006) in the study of the poposauroid Qianosuchus mixtus Li et al., 2006 (Fig. S1G).

Recently, two large-scale phylogenetic analyses have been conducted with a more careful examination of Gracilisuchus material. The analysis of Brusatte et al. (2010) included an extensive taxon sampling, although somewhat biased towards 'rauisuchian' archosaurs and lacking good representation of other crocodile-line archosaurs. As a consequence, the recovery of Gracilisuchus as the closest sister taxon to Erpetosuchus + Crocodylomorpha might, in part, be a result of poor sampling in this region of the tree (Fig. S1H). Nesbitt's (2011) analysis sampled a larger number of taxa and characters, but Gracilisuchus was recovered in an unresolved polytomy at the base of Suchia (Fig. S1I). Despite the lack of a compelling resolution of its phylogenetic position and incomplete knowledge of its anatomy, Gracilisuchus has been frequently used as an outgroup in several analyses focused on the relationships of non-crocodyliform crocodylomorphs, the so-called 'Sphenosuchia' (e.g. Clark, Sues \& Berman, 2000; Clark \& Sues, 2002; Sues et al., 2003) or the more derived Crocodyliformes (e.g. Clark, 1994; Clark et al., 2004; Pol, 2003, 2005; Pol \& Gasparini, 2009; Pol et al., 2012; Fig. S1J). Recently, some new insights into our knowledge and understanding of Gracilisuchus have been attempted. Lecuona \& Desojo (2011) restudied the pelvic girdle and hind limb of a well-preserved and almost complete specimen (PVL 4597), recognizing several new characters, and Lecuona (2013) studied the anatomy of the six specimens known for this species and incorporated 
new data into a phylogenetic framework. Subsequently, Butler et al. (2014) revisited the anatomy and phylogenetic relationships of Turfanosuchus dabanensis Young, 1973 and Yonghesuchus sangbiensis Wu, Liu \& $\mathrm{Li}, 2001$, two early suchians that also have been the subject of multiple disparate phylogenetic hypotheses and not related to each other (Young, 1973; Parrish, 1993; Wu \& Russell, 2001; Wu et al., 2001; Dilkes \& Sues, 2009; Ezcurra, Lecuona \& Martinelli, 2010). Butler et al. (2014) concluded that both these species were closely related to Gracilisuchus, with the three of them forming the newly named clade Gracilisuchidae (Butler et al., 2014).

The present contribution is focused on the description of the postcranial axial skeleton, forelimb fragments and osteoderms of G. stipanicicorum, as well as its phylogenetic position among Pseudosuchia, and particularly Suchia. This contribution is part of a larger anatomical study of the complete skeleton of Gracilisuchus, including the cranium and postcranium and an updated phylogenetic analyses. The latter analysis was performed including all the new anatomical information gathered from the revision of the complete skeleton; however, the cranial material of G. stipanicicorum will be discussed in another contribution, to make the length of the present contribution manageable. As a result of the anatomical examination of the specimens, it was possible to identify new diagnostic characters, thus improving the diagnosis of the species and genus. The phylogenetic relationships of G. stipanicicorum were evaluated based on an extensive phylogenetic analysis of Archosauriformes expanding a previous dataset (Nesbitt, 2011) in terms of both taxon and character sampling.

\section{MATERIAL AND METHODS}

The material described here is the postcranium of all the specimens of $G$. stipanicicorum not described previously (see Lecuona \& Desojo, 2011), focused on the specimens deposited in Argentinean collections (PULR 08, PVL 4597, PVL 4612) and comparing with those housed in the Collection of the Harvard Museum (MCZ 4116, MCZ 4117, MCZ 4118). The postcranial elements described here consist of vertebral series with ribs and haemal arches, fragmentary forelimb and osteoderms. The preserved elements of G. stipanicicorum are summarized in Figure 4. Measurements of the skeletal elements described (except the atlas intercetrum) are presented in the Supplementary Information, Tables S1-S9. Methods related to the phylogenetic analysis are given below.

Clade names used here follow Nesbitt (2011), and the term 'rauisuchians' refers to the paraphyletic group of non-crocodylomorphs, paracrocodylomorphs plus Ticinosuchus ferox Krebs, 1965.

\section{INSTITUTIONAL ABBREVIATIONS}

AMNH FR, American Museum of Natural History, New York, USA; GPIT, Institut für Geowissenschaften, Universität Tübingen, Germany; ISI, Geological Studies Unit of the Indian Statistical Institute, Kolkata, India; IVPP, Institute of Vertebrate Paleontology and Paleoanthropology, Academia Sinica, Beijing, China; MCZ, Museum of Comparative Zoology, Harvard University, Cambridge, MA, USA; MHI, Muschelkalkmuseum Ingelfingen, Germany; MLP, Museo de La Plata, La Plata, Buenos Aires Province, Argentina; NCSM, North Carolina Museum of Natural Sciences, Raleigh, NC, USA; PULR, Museo de Paleontología, Universidad Nacional de La Rioja, La Rioja Province, Argentina; PVL, Paleontología de Vertebrados, Instituto Miguel Lillo, Universidad Nacional de Tucumán, Tucumán Province, Argentina; PIMUZ, Paläontologisches Institut und Museum der Universität, Zürich, Switzerland; PVSJ, Museo de Ciencias Naturales, Universidad Nacional de San Juan, San Juan Province, Argentina; SAM-PK, Iziko South African Museum, Cape Town, South Africa; SMNS, Staatliches Museum für Naturkunde, Stuttgart, Germany; UNC, University of North Carolina, Raleigh, NC, USA; USNM, National Museum of Natural History, Washington, DC, USA.

\section{SYSTEMATIC PALAEONTOLOGY}

ARCHOSAURIA COPE, 1869

SENSU GAUTHIER \& PADIAN, 1985

PSEUDOSUCHIA ZITTEL, 1887-1890

SENSU GAUTHIER \& PADIAN, 1985

SUCHIA KREBS, 1974

SENSU BENTON \& CLARK, 1988

GRACILISUCHIDAE BUTLER ET AL., 2014

GENUS GRACILISUCHUS ROMER, 1972A

Diagnosis: Same as the type species by monotypy.

GRACILISUCHUS STIPANICICORUM ROMER, 1972A

(FIGS 4-16, S2-S5)

\section{Holotype}

PULR 08, incomplete cranium represented by the right side of the rostrum, the parietal, palatal and occipital regions, and disarticulated left premaxilla, maxilla, nasal and jugal; a disarticulated single mandibular ramus; an incomplete presacral series of vertebrae partially articulated, partially exposed cervical series 
from the axis to cervical 8 , and a probable atlas intercentrum, incomplete dorsal series from dorsal 9 to 16 , and incomplete first sacral vertebra; 13 right and two left articulated dorsal ribs; an articulated series of paramedian osteoderms; distal ends of the right scapula and humerus; two metapodia and few gastralia. Some elements formerly interpreted as belonging to this specimen are no longer assigned to it (see below).

\section{Referred material}

MCZ 4116A (in part), several skeletal elements are preserved in this slab, but only a few of them can be assigned to G. stipanicicorum, such as a partial cranium, incomplete articulated caudal vertebral series and articulated ischia. MCZ 4117, well-preserved and nearly complete cranium, a single isolated osteoderm. MCZ 4118, incomplete cranium; articulated cervical vertebrae from axis to cervical 7, articulated with osteoderms and a few ribs (Romer's 'Series 1'); a series of six probable cervicodorsal centra articulated with ribs (Romer's 'Series 2'); and a dorsal series of at least nine elements (Romer's 'Series 5'). Other material under the same collection number formerly assigned to G. stipanicicorum cannot be interpreted here as this species due to the lack of diagnostic characters or clearly contrasting morphology with the Gracilisuchus holotype or other certain specimens. PVL 4597, nearly complete and articulated skull and mandible, exposing some teeth; an almost complete presacral vertebral series with articulated ribs and paramedian dorsal osteoderms, two sacral vertebrae, an incomplete caudal vertebral series with articulated haemal arches, both ilia, left pubis, both ischia, almost complete left hind limb, fragmentary right hind limb and several undetermined bone fragments (see Lecuona \& Desojo, 2011). PVL 4612, nearly complete skull, articulated with the left mandibular ramus, exposing the palate.

\section{Locality, horizon and age}

Chañares type locality, Chañares Formation, Ischigualasto - Villa Unión Basin, La Rioja Province, north-west Argentina, $3 \mathrm{~km}$ north of the northern branch of the Chañares River and $5 \mathrm{~km}$ south-west of the Puerta de Talampaya (Sereno \& Arcucci, 1994) (Fig. 1). The Chañares Formation has been usually and consistently interpreted as Ladinian in age (Stipanicic, 1983; Rogers et al., 1993, 2001). However, recent radioisotopic analyses constrained the age of a Chañares Formation fossiliferous horizon to between 236 and 234 Mya (Irmis et al., 2013; Marsicano et al., 2016), thus reaching an early Carnian age (Late Triassic) and confirming the hypotheses of Desojo, Ezcurra \& Schultz (2011) and Fiorelli et al. (2013).

\section{Emended diagnosis}

Lightly built pseudosuchian with a total skull length that slightly exeeded $90 \mathrm{~mm}$ (in the largest specimen, PVL 4612 , with incomplete anterior end of the snout) and largest preserved femur of $80 \mathrm{~mm}$ in total length (PVL 4597, which is one of the largest specimens), diagnosed by the following unique combination of characters (autapomorphies marked with an asterisk): relatively large skull openings: antorbital fenestra occupying between 30 and $36 \%$, antorbital fossa between 36 and $40 \%$ and orbit between 35 and $42 \%$ of the anteroposterior length of skull roof (measured up to the posterior end of the parietals); supratemporal fenestra wider than long*; sclerotic ring with ossicles in lateral contact not overlapped; straight posterior edge of postorbital process of jugal*; presence of postfrontal, with a long lateral process that projects over the postorbital bar*; presence of a small triangular postparietal; large posttemportal foramen in proportion to the width of the occipital region; laterally extended anterior process of squamosal; premaxillary teeth with no mesial carina, distal carina slightly marked and no mesial or distal denticles; postzygapophyseal facet of the axis in the horizontal plane and with the longitudinal axis posteriorly directed*; high and vertical anterior border of the axial neural spine*; longitudinal median ventral keel in the axial centrum; poorly developed ventral keel of cervical vertebrae; mid-dorsal region of cervical vertebrae neural arch with a circular depression; spine table in posterior cervical vertebrae (at least in cervicals 4 of PVL 4597, and 6 and 7 of MCZ 4118); distal (lateral) end of first sacral rib slightly expanded relative to the proximal (medial) portion*; lack of a well-defined acetabular surface on the pubis; thin L-shaped lamina on proximal pubic apron; lateroventral corner of pubic peduncle with a short bony tongue; ischiadic symphysis proximally located*; proximodistally elongated and poorly developed iliofibular trochanter on fibula; staggered paramedian osteoderms; longitudinal keel on dorsal surface of osteoderms slightly medially located with respect to the centre of the element and laterally bent (modified from Lecuona \& Desojo, 2011).

\section{Comments on the holotype slab material}

Due to taphonomic processes, the holotype of G. stipanicicorum (PULR 08) consists of an articulated specimen found together with a mixture of remains belonging to different taxa. All these scattered remains were found closely associated and partially disarticulated, hampering the assignment of each element to a definite taxon, and particularly to the holotype of Gracilisuchus. Subsequent authors assigned and reassigned several elements of the slab to different taxa, including to PULR 08 itself (Sereno \& Arcucci, 1994). This section will summarize, clarify and identify each fossil element found in the slab (Figs 2,3). 


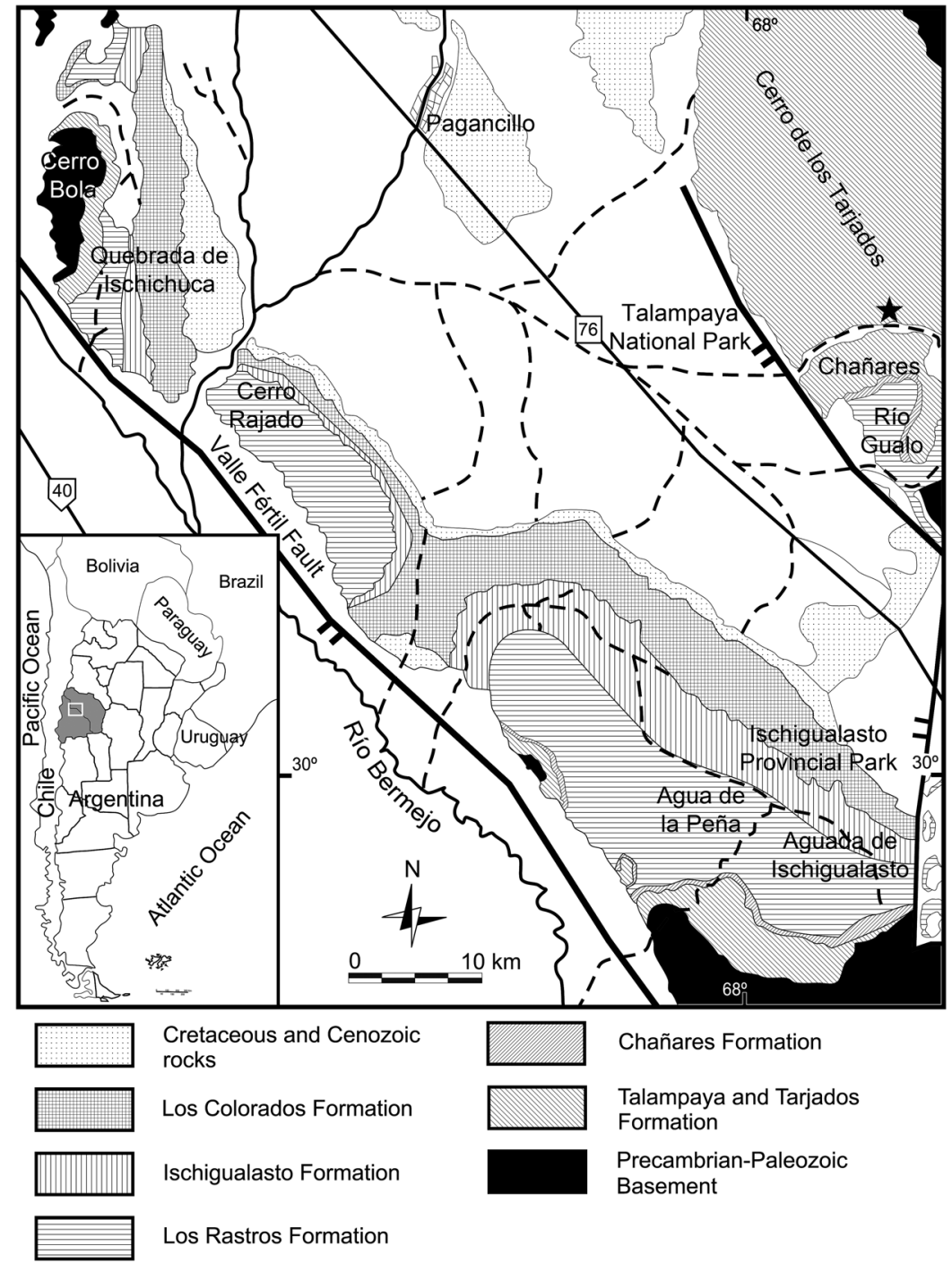

Figure 1. Geographical location of Ischigualasto - Villa Unión Basin, La Rioja and San Juan, north-west Argentina. Star shows the outcrop location. Modified from von Baczko, Desojo \& Pol (2014).

Among the remains assigned by Romer to Gracilisuchus there is an articulated vertebral series disconnected from the rest of the skeleton, interpreted as most of the tail (Romer, 1972a: 16), and originally assigned to the holotype of 'Lagosuchus talamapayensis' (PULR 09; Romer, 1971b: 5) but later to G. stipanicicorum (Romer, 1972a: 16; 1972b: 4). Nevertheless, this vertebral series was subsequently interpreted as cervical and dorsal vertebrae of the archosauriform Tropidosuchus romeri (PULR s/n; Sereno \& Arcucci, 1994: 55, fig. 1; 'Series A', Fig. 2). A second articulated vertebral series with osteoderms (Romer, 1972a: 16; 'Series B', Fig. 2) represents cervical vertebrae from the axis to the ninth vertebra; the morphology of the vertebrae and osteoderms indicates that they do not belong to a specimen of Gracilisuchus, but their morphology and the proximity to the skeletal remains of Tropidosuchus romeri suggest that this series could be referred to the latter taxon (M. Ezcurra, pers. comm.). Two additional series were mentioned by Romer but could not be identified in the slab: a series of 14 and another of 15 vertebrae (Romer, 1972a: 16). A right scapulocoracoid was described and illustrated (Romer, 1972a: fig. 8a) found close to the skull of Gracilisuchus (Figs 2,3) and above the 'Series B'. This element contacts the right and left humeri, almost articulating with the right one (Romer, 1972a: 19); the left pectoral girdle is not present, although it may still be covered by sediment; both radii and ulnae were preserved in articulation with their corresponding humeri (Figs 2, 3; Romer, 1972a: fig. 8a). None of the pectoral girdle and forelimb elements originally assigned to the holotype of Gracilisuchus belong 
to this individual, because the holotype already has an articulated fragmentary right scapula and humerus, because of the intermixing nature of the fossil elements in the whole slab and because of their distance from the articulated skeleton of the holotype.

An ilium was also originally described for the holotype of Gracilisuchus but none of the three ilia preserved in the slab is identified as such. One of the ilia present in the slab corresponds to the right ilium of 'Lagosuchus talampayensis' (PULR 09, Sereno \& Arcucci, 1994; Fig. 3), which is in contact with other pelvic girdle elements (Sereno \& Arcucci, 1994: fig. 1). The second ilium is preserved closely associated with the femur of Tropidosuchus and was interpreted as belonging to this species (Sereno \& Arcucci, 1994; Fig. 2). The third and largest ilium is isolated and close to the skull of Gracilisuchus and still remains indeterminate (Fig. 3).
The articulated right hind limb originally assigned to Gracilisuchus (Romer, 1972a: 20) is located in the centre of the slab, in contact with the ilium and from one side of the slab is articulated with a probable fibula and part of the autopodium (Fig. 2), and from the other side of the slab with the probable tibia and autopodium (Fig. 3). This hind limb was restudied and reassigned to Tropidosuchus romeri (PULR s/n, Sereno \& Arcucci, 1994: 53). A left femur and tibia is located close to the skull and cervical series of Gracilisuchus (Fig. 2); based on the robustness and well-developed fourth trochanter of the femur they are interpreted as belonging to Tropidosuchus, but this needs to be studied more deeply. A third hind limb is present next to the one just mentioned (Fig. 2) and was assigned to the holotype of 'Lagosuchus talampayensis' (PULR 09; Romer, 1971b, 1972b; Sereno \& Arcucci, 1994). Finally, a right foot

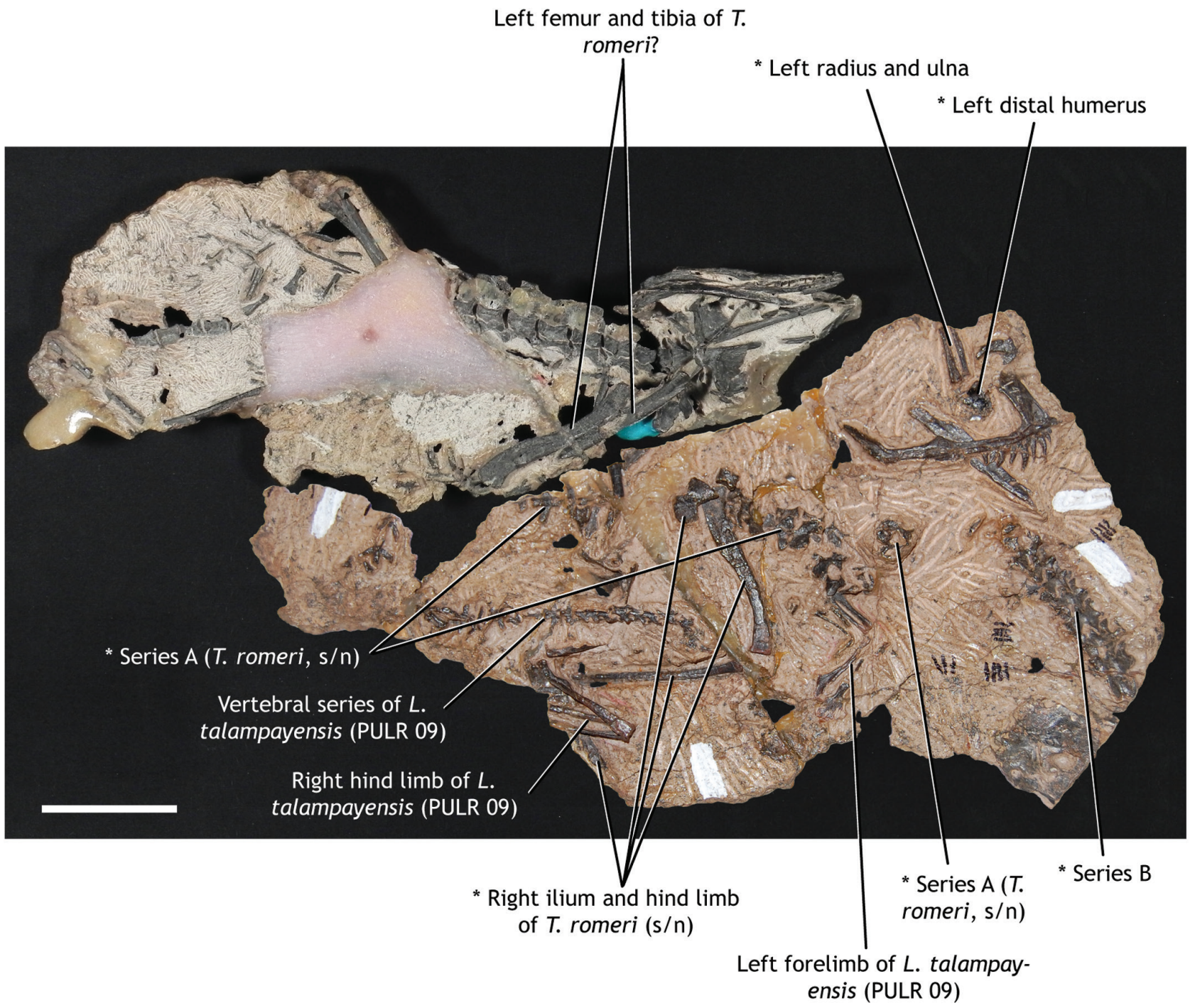

Figure 2. Reconstruction of the slab where the holotype of G. stipanicicorum (PULR 08) was found in ventral view of the specimen. The elements originally assigned to Gracilisuchus are marked with an asterisk (Romer, 1972a). Scale bar, $5 \mathrm{~cm}$. 
assigned to the holotype of Gracilisuchus corresponds to the autopodium of Tropidosuchus in articulation with the anteriorly mentioned right hind limb (Fig. 3).

\section{Description}

Cervical vertebrae: The cervical series is nearly complete in Gracilisuchus when combining the whole hypodigm. In the holotype, from the axis to cervical vertebra 8 and a disarticulated probable atlas intercentrum are preserved. The referred specimen PVL 4597 has better preserved cervical vertebrae 3-8, and in MCZ 4118, from the axis to cervical vertebra 7 are present.

Atlas intercentrum?: A U-shaped element was found between the axis and the skull of the holotype specimen and tentatively interpreted as an atlas intercentrum

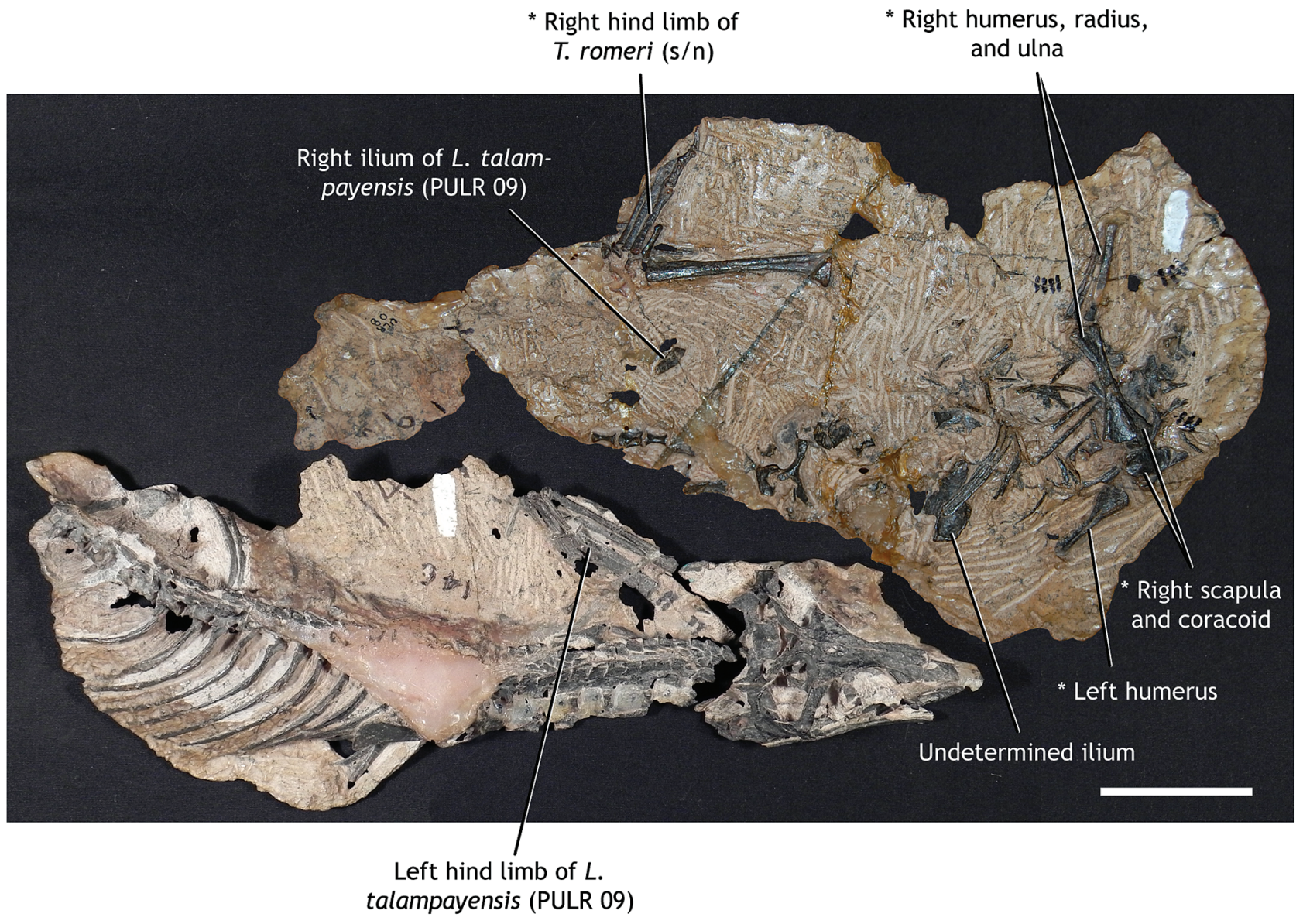

Figure 3. Reconstruction of the slab where the holotype of G. stipanicicorum (PULR 08) was found in dorsal view of the specimen. The elements originally assigned to Gracilisuchus are marked with an asterisk (Romer, 1972a). Scale bar, $5 \mathrm{~cm}$.

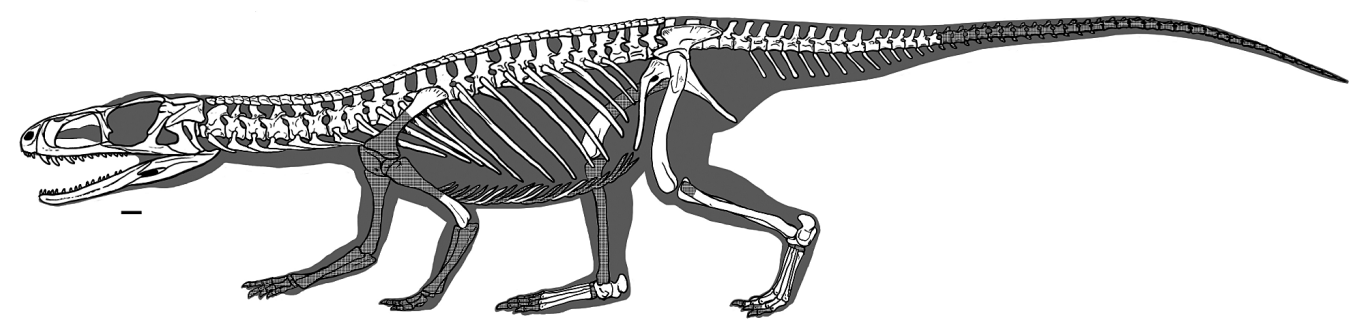

Figure 4. Reconstruction of the G. stipanicicorum skeleton, showing the missing elements in grey. Illustration by Jorge González. Scale bar, $1 \mathrm{~cm}$. 


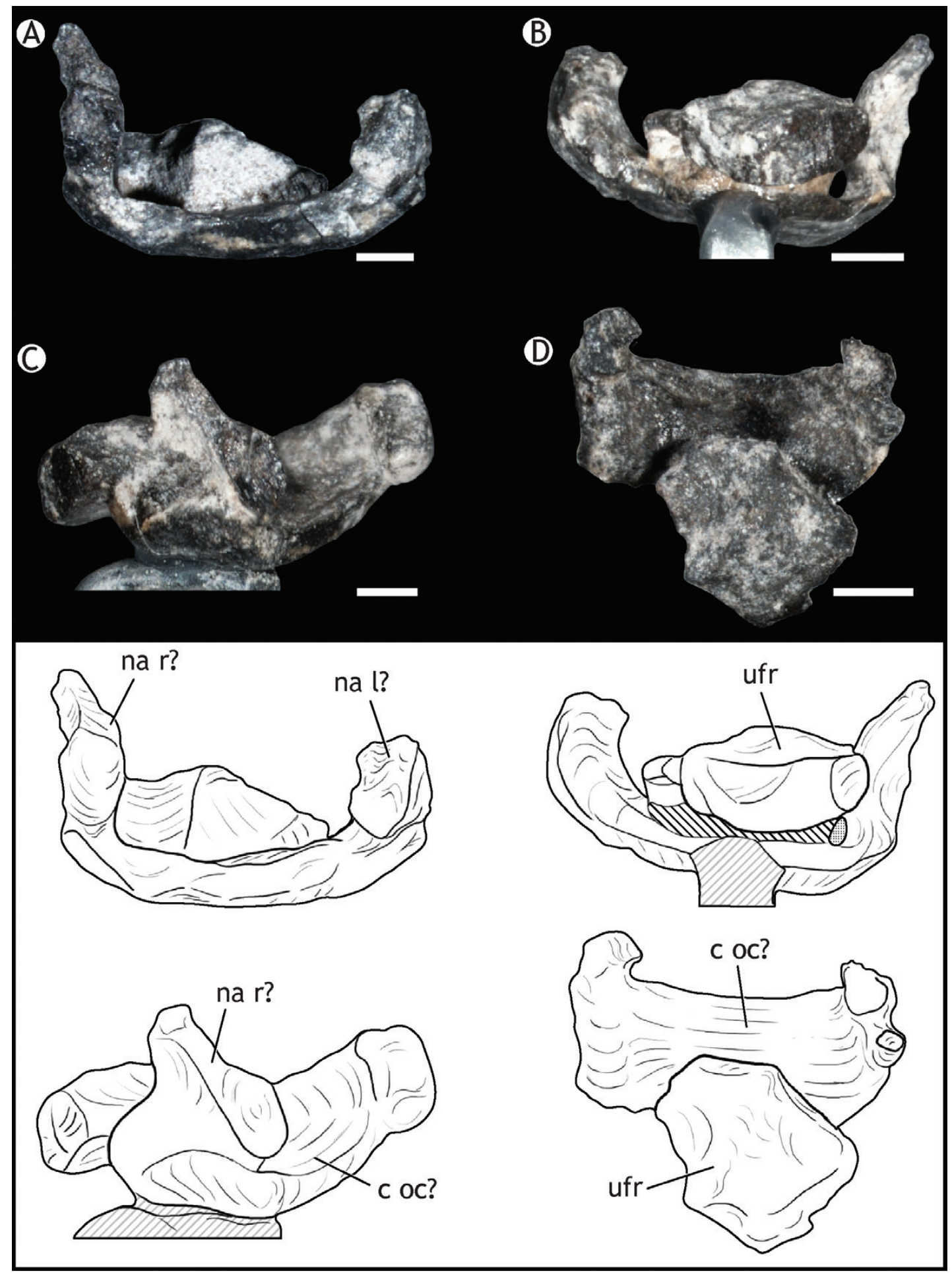

Figure 5. Gracilisuchus stipanicicorum (PULR 08), putative atlas intercentrum and neurapophysis in anterior (A), posterior (B), lateral (C) and dorsal (D) views. References in drawings: grey stripes, metal support. Abbreviations: c oc?, putative contact with occipital condyle; na l?, putative left neurapophysis; na r?, putative right neurapophysis; ufr, undetermined fragment. Scale bars, $1 \mathrm{~mm}$. 
fused to its neurapophyses (Fig. 5). This is the most plausible interpretation for this element, but some doubts still remain. The ventral region of the element is very thin, with an irregular concave anterior border and a convex posterior one in dorsal or ventral views. Its dorsal surface bears the articulation for the occipital condyle, which is lateromedially concave and anteroposteriorly flat, almost twice as wide as tall (5.65 vs. $2.76 \mathrm{~mm}$ ). The neurapophyses are short, projecting dorsoanteriorly from the lateral edges of the interpreted articular surface for the occipital condyle.

Axis: This vertebra is preserved in specimens PULR 08 and MCZ 4118 ('Series 1'). The axis is the first vertebra well preserved in PULR 08 (Fig. 6), whereas in MCZ 4118 only the posterior part of the centrum and neural spine are preserved. The centrum is short in the holotype (PULR 08; Supporting Information, Table S1) and unfused to the neural arch, where a small separation between each part of the vertebrae can be seen. In contrast, in MCZ 4118 , the suture is completely obliterated, suggesting a possible older ontogenetic stage (Brochu, 1996; Irmis, 2007) of the referred specimen. In PULR 08, the centrum has a strong transverse compression in almost its entire length, likely to be a preservational result, only slightly expanded in the anterior and posterior ends to form the articular facets. The compression also occurs in its dorsoventral height but a triangular dorsal projection and the complementary shape on the neural arch can still be observed. This triangular outline contrasts with the dorsally curved neurocentral sutures of other archosauromorphs that could be compared, such as Euparkeria capensis Ewer, 1965 (Ewer, 1965; SAM-PK6047A, Euparkeria: An Image Library), Turfanosuchus dabanensis (IVPP V3237, photographs provided by M. Ezcurra), the 'rauisuchians' Fasolasuchus tenax Bonaparte, 1978 (PVL 3850) and Saurosuchus galilei Reig, 1959 (PVSJ 32), and the crocodylomorphs Sphenosuchus acutus Haughton, 1915 (SAM-PK-3014) and Dibothrosuchus elaphros Simmons, 1965 (Wu \& Chatterjee, 1993). The ventral-most middle region of the centrum is only $0.84 \mathrm{~mm}$ wide, representing 0.2 times the anterior width, creating a very narrow keel in ventral view. A ventral keel is also seen in the basal archosauriform Euparkeria capensis, but only in the posterior region of the centrum (Ewer, 1965). The same condition is seen in the ornithosuchid Riojasuchus tenuisceps Bonaparte, 1969 (PVL 3827); a long keel is

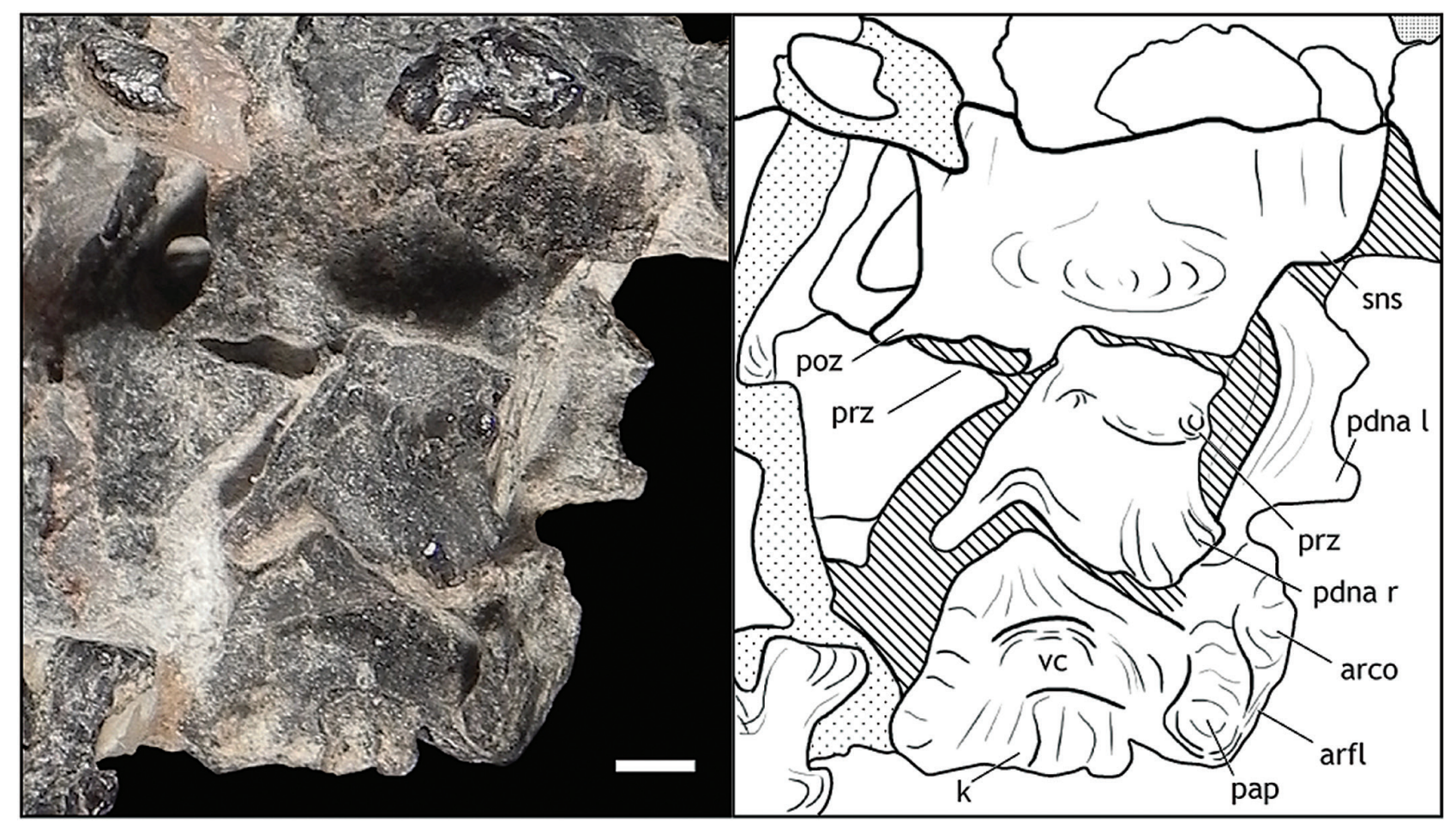

Figure 6. Gracilisuchus stipanicicorum (PULR 08), axis in right lateral view. References in drawings: stripes, sediment; loose spots, glue; dense spots, empty regions. Abbreviations: arco, dorsal concave region of anterior facet; arfl, ventral flat region of anterior facet; $\mathrm{k}$, keel; pap, parapophysis; pdna l, left peduncle of neural arch; pdna r, right peduncle of neural arch; poz, postzygapophysis; prz, prezygapophysis; sns, anterior 'step'-like structure in the neural spine; vc, vertebral centrum. Scale bar, $2 \mathrm{~mm}$. 

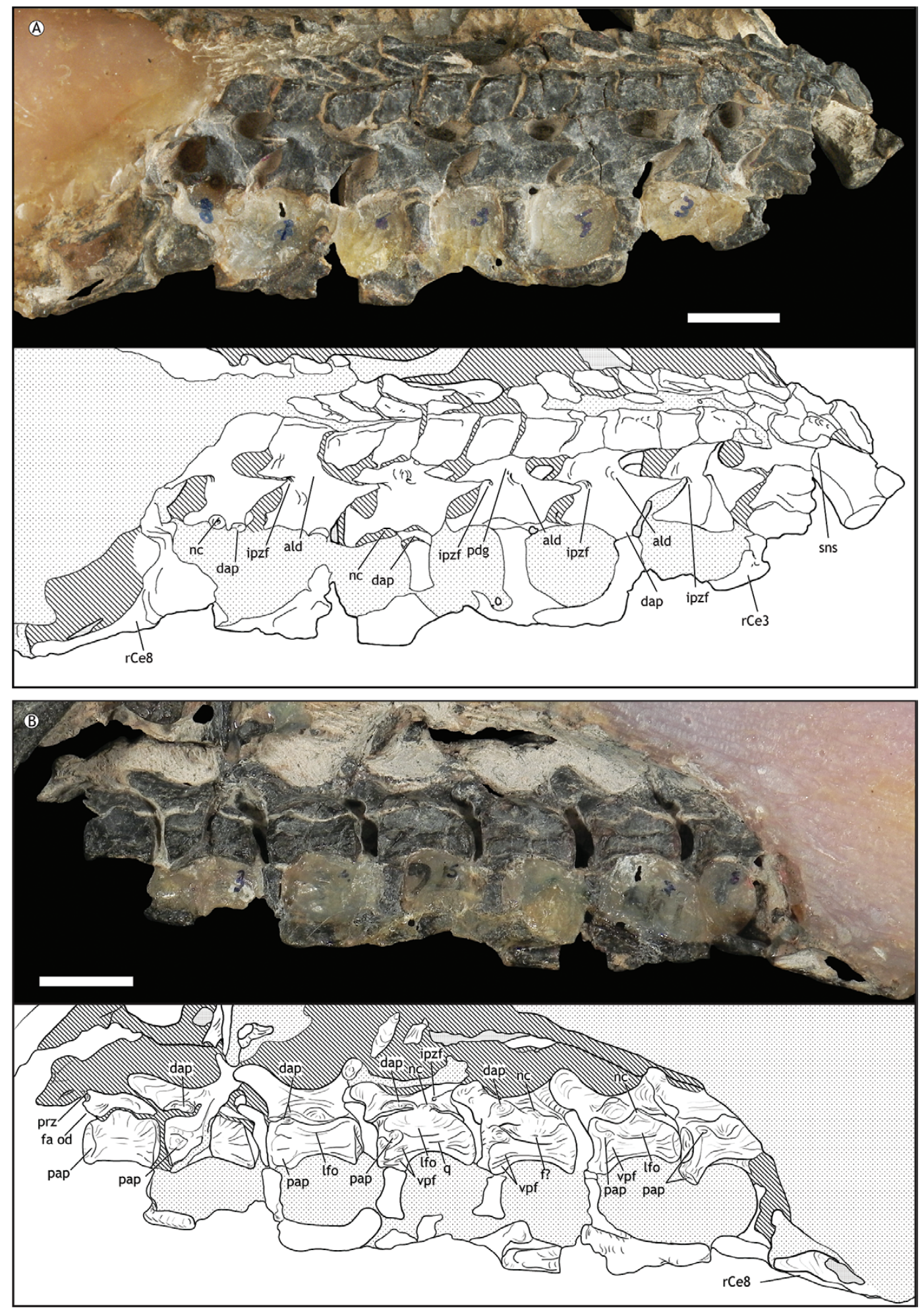

Figure 7. Gracilisuchus stipanicicorum (PULR 08), preserved cervical vertebrae in right lateral (A) and left lateral (B) views. References in drawings: stripes, sediment; loose spots, glue; dense spots, empty regions. Abbreviations: ald, anterolateral depression; dap, diapophysis; f?, foramen?; fa od, facet for odontoid process; ipzf, infrapostzygapophyseal depression; k, keel; lfo, longitudinal lateral fossa on vertebral centrum; nc, inverted V-shaped notch in vertebral centra; pap, parapophysis; pdg, posterodorsal groove; prz, prezygapophysis; rCe3-rCe8: cervical ribs 3-8; sns, anterior 'step'-like structure in axial neural spine; vpf, ventral parapophyseal fossa. Scale bars, $1 \mathrm{~cm}$. 
also present in some phytosaurs such as Parasuchus hislopi Lydekker, 1885 (ISI R43) and Smilosuchus gregorii Camp, 1930 sensu Long \& Murry, 1995 (USNM 18313), in the aetosaur Stagonolepis robertsoni Agassiz, 1844 (Walker, 1961) and the loricatan Saurosuchus galilei (PVSJ 32), but contrasting with the two parallel keels of Postosuchus alisonae Peyer et al., 2008, and the posteriorly bifurcated keel of Arizonasaurus babbitti Welles, 1947 (Nesbitt, 2005).

The parapophysis is represented in the holotype by a well-defined tall and narrow surface in the right anterior end of the centrum, where its ventral half is wider than the dorsal, for the contact with the capitulum of the axial rib (Fig. 6); in the left side of the vertebrae the parapophysis is not recognized. The articular parapophyseal facet is located directly on the surface of the vertebral centrum with no parapophyseal peduncle, which is in contrast to more posterior vertebrae that possess the articular facet at the end of the parapophyseal peduncle. This apophysis in Gracilisuchus may have been located in the contact between the centrum and odontoid process of the axis, as occurs in living crocodilians (Mook, 1921: 70), but it cannot be determined in the odontoid process because of the apparent absence of this element. The anterior surface of the axis of Gracilisuchus was in contact with the supposedly unpreserved odontoid process, but that could be represented by one of the undetermined elements preserved anterior to the axis in the holotype slab. The diapophysis, articulation for the rib tubercle, cannot be recognized in PULR 08 because it would be located in the odontoid process. The pedicle of the axial neural arch finishes slightly anterior to the anterior margin of the centrum in PULR 08, suggesting an articulation with the posterodorsal region of the anterior odontoid process. The unfused condition of the axial centrum and the odontoid supports an early ontogenetic stage for the holotype of Gracilisuchus, considering that in living crocodilians [e.g. Alligator mississippiensis (Daudin), 1802; A. sinensis Fauvel, 1879; Crocodylus acutus (Cuvier), 1807] these two elements become fused in skeletally more mature stages, and starts before the centrum-arch fusion (Brochu, 1996). The latter suture is also visibly unfused in the holotype specimen, but it cannot be determined whether the odontoid-centrum suture had already started to fuse.

The anterior articular facet of the centrum is dorsoventrally elongated and shows a surface with a double curvature, where the ventral half is flat and the dorsal one is convex (Fig. 6). The posterior articular

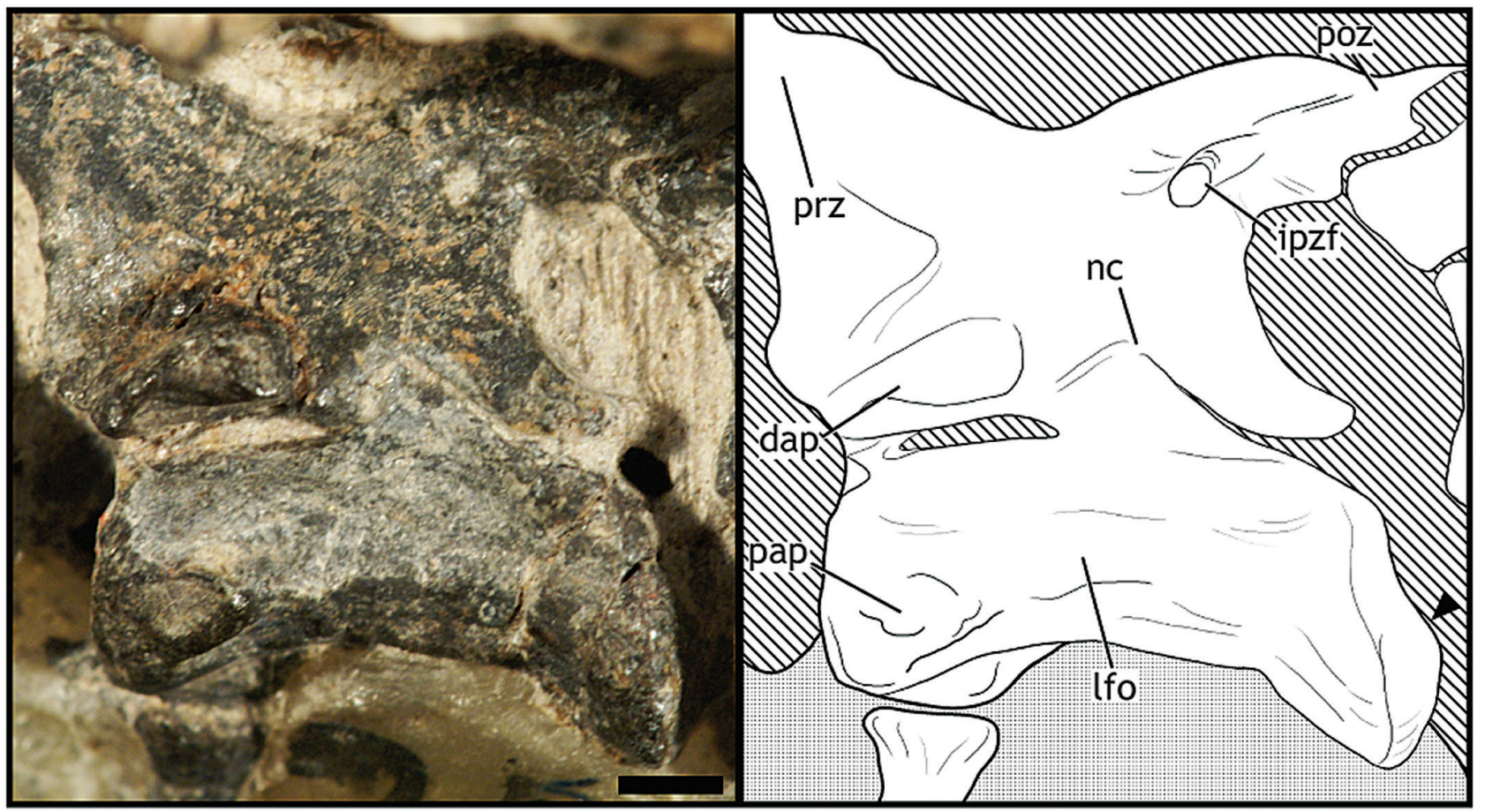

Figure 8. Gracilisuchus stipanicicorum (PULR 08), cervical vertebra 5 in left lateral view. Arrow indicates the concaveconvex morphology of the posterior articular facet. References in drawings: stripes, sediment; loose spots, glue; dense spots, empty regions. Abbreviations: dap, diapophysis; ipzf, infrapostzygapophyseal depression; lfo, longitudinal lateral fossa on vertebral centrum; nc, inverted V-shaped notch in vertebral centra; pap, parapophysis; poz, postzygapophysis; prz, prezygapophysis. Scale bar, $1 \mathrm{~cm}$. 
facet is straight and posteroventrally inclined in lateral view. The neural arch is lower and wider than the centrum (Table S1).

In the axial prezygapophysis of the holotype, the facet is located directly on the surface of the arch, lacking a prezygapophyseal pedicle (Fig. 6). It is small but anteroposteriorly elongated, located dorsally on the anterolateral margin of the neural arch, at mid-height of the neural canal and below the level of the postzygapophysis. The postzygapophyseal facet is located on the posteroventral corner of the neural spine and projects posteriorly to the posterior end of the centrum. In MCZ 4118 the postzygapophyses project posterolaterally from the neural spine, contrasting with the posteriorly directed postzygapophyses of PULR 08. The postzygapophysis of Gracilisuchus resembles those of the gracilisuchid Turfanosuchus dabanensis (IVPP V3237, photographs provided by M. Ezcurra) and the erpetosuchid Erpetosuchus granti (Benton \& Walker, 2002: fig. 3A) in its extention posterior to the posterior articular facet of the centrum.

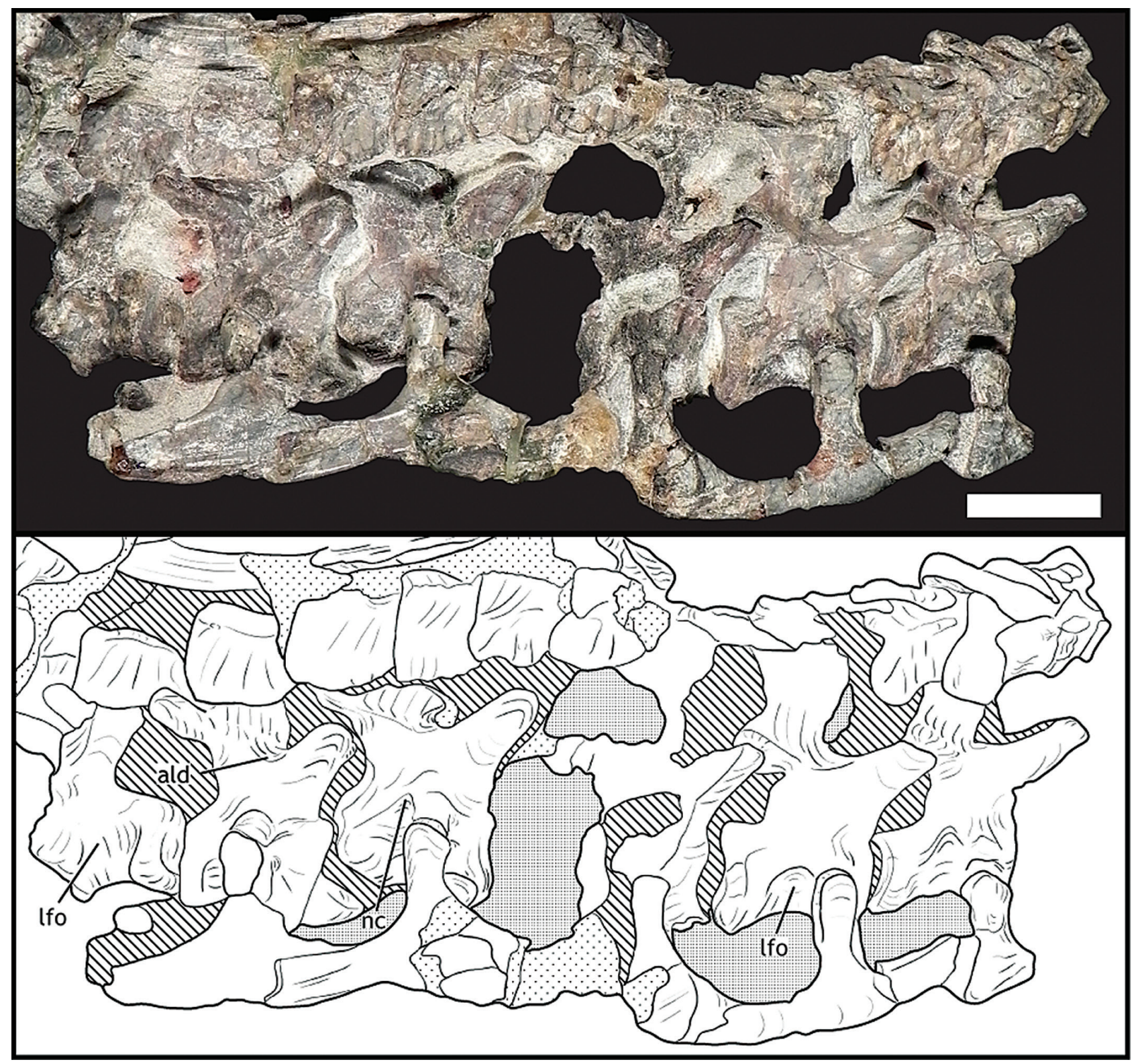

Figure 9. Gracilisuchus stipanicicorum (PVL 4597), cervical vertebrae 3-8 in right lateral view. References in drawings: stripes, sediment; loose spots, glue; dense spots, empty regions. Abbreviations: ald, anterolateral depression; lfo, longitudinal lateral fossa on vertebral centrum; nc, inverted V-shaped notch in vertebral centra. Scale bar, $1 \mathrm{~cm}$. 


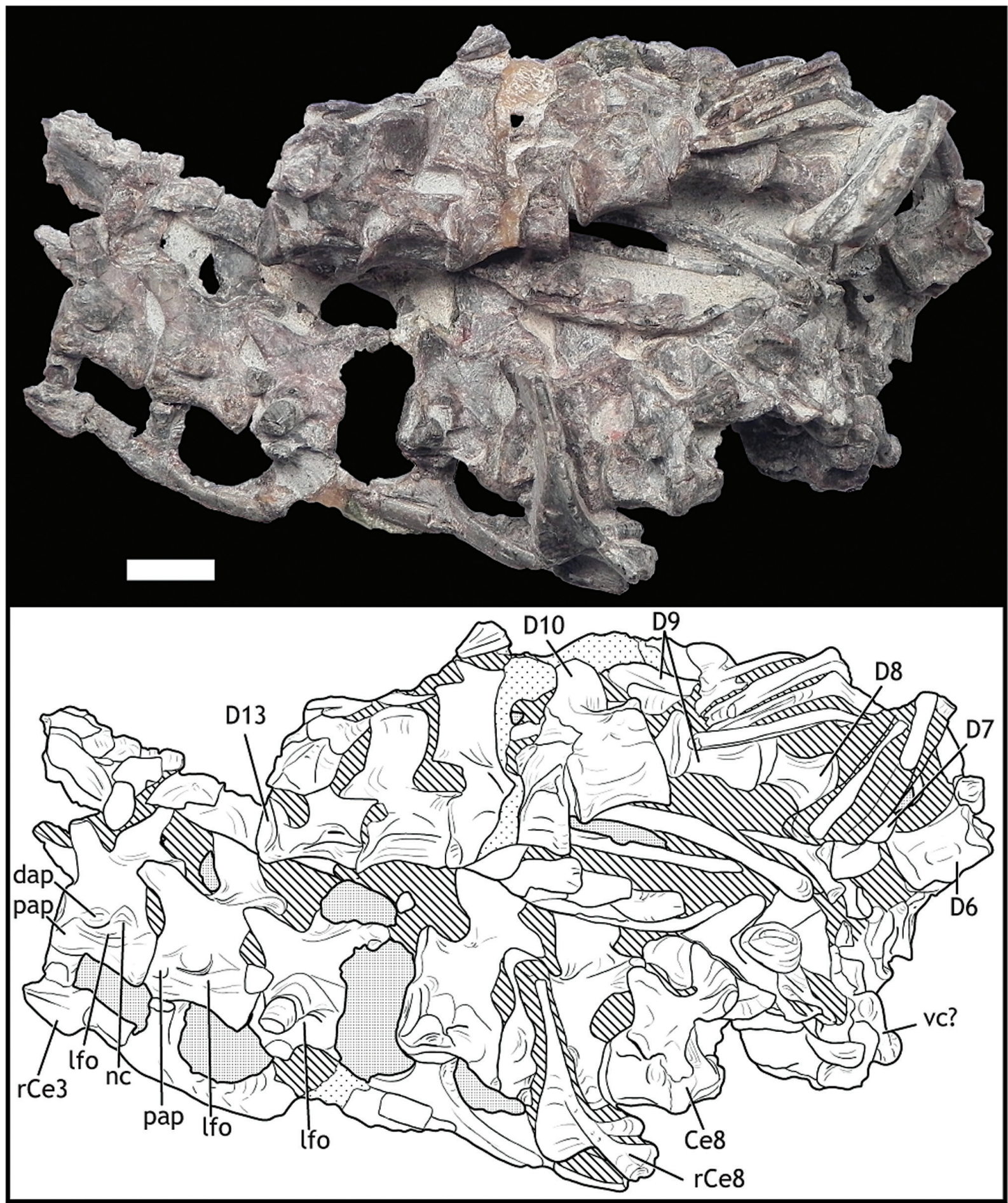

Figure 10. Gracilisuchus stipanicicorum (PVL 4597), cervicodorsal vertebrae in left lateral view of cervical series. References in drawings: stripes, sediment; loose spots, glue; dense spots, empty regions. Abbreviations: Ce3-Ce8, cervical vertebrae 3-8; D6-D16, dorsal vertebrae 6-16; dap, diapophysis; lfo, longitudinal lateral fossa of vertebral centrum; nc, inverted V-shaped notch in vertebral centra; pap, parapophysis; rCe3-rCe8, cervical ribs 3-8; vc?, putative vertebral centrum. Scale bar, $1 \mathrm{~cm}$. 
In PULR 08, the neural spine is in contact with the dorsal osteoderms, and thus its height can only be estimated and its basal length measured, which is the longest of the cervical series (Table S1). The neural spine of MCZ 4118 is visible in its anterodorsal border, which slants ventrally. The lateral surface of the neural spine bears a shallow depression anterodorsally to the postzygapophysis, which is wider in MCZ

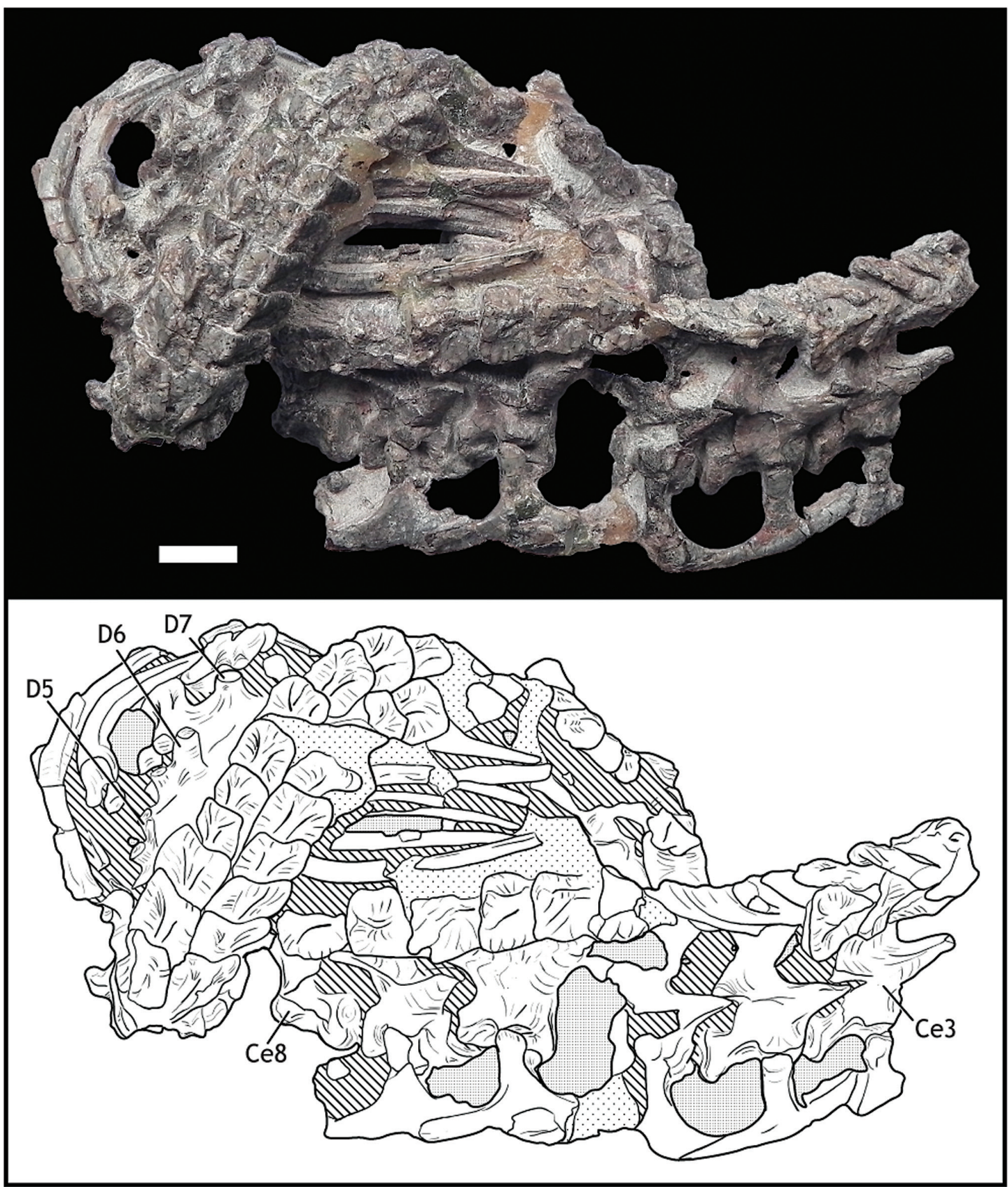

Figure 11. Gracilisuchus stipanicicorum (PVL 4597), cervicodorsal vertebrae in right lateral view of cervical series. References in drawings: stripes, sediment; loose spots, glue; dense spots, empty regions. Abbreviations: Ce3-Ce8, cervical vertebrae 3-8; D5-D7, dorsal vertebrae 5-7. Scale bar, $1 \mathrm{~cm}$. 
4118 than in PULR 08. In addition, the neural spine of the holotype shows a step-like anterior border in lateral view, where the ventral half of this border is at the same level as the centrum and the dorsal half is more anterior (Fig. 6). The posterior border of the neural spine is posteriorly directed and forms a concave outline with the postzygapophysis in lateral aspect, which is similar to Turfanosuchus dabanensis (IVPP
V3237), but contrasts with Erpetosuchus, which shows an almost straight outline (Benton \& Walker, 2002: fig. 3A). The neural canal of PULR 08 is wide and high (Table S1), being almost as wide as the centrum.

Cervical vertebrae 3-8: All of the postaxial cervical vertebrae of Gracilisuchus (PULR 08, PVL 4597, MCZ 4118) have spool-shaped centra, lacking
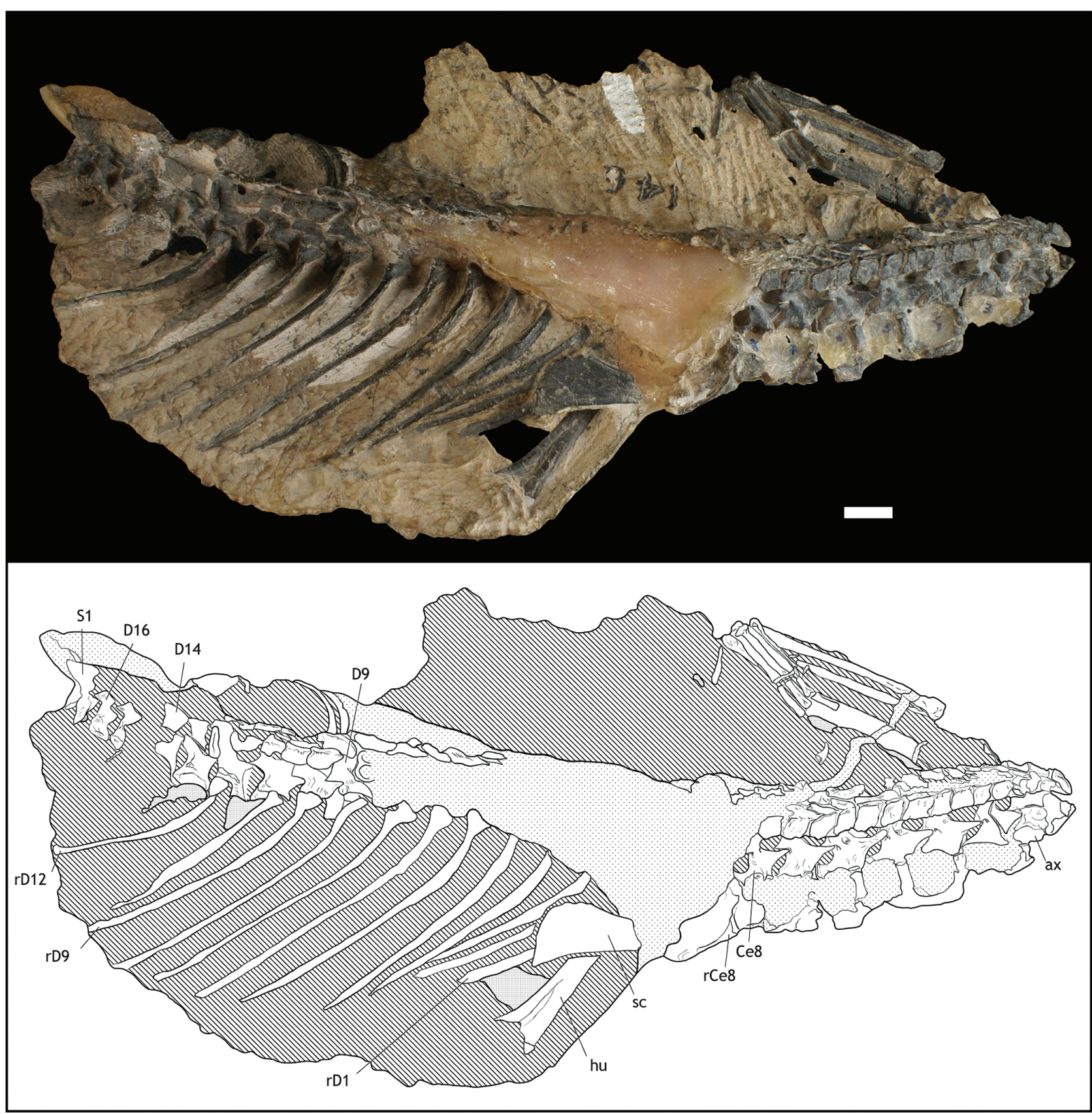

Figure 12. Gracilisuchus stipanicicorum (PULR 08), postcranium in right lateral and dorsal view. References in drawings: stripes, sediment; loose spots, glue; dense spots, empty regions. Abbreviations: ax, axis; Ce3-Ce8, cervical vertebrae 3-8; D9-D16, dorsal vertebrae 9-16; hu, humerus; rCe3-rCe8, cervical ribs 3-8; rD1-rD12, dorsal ribs 1-12; S1, sacral vertebra 1 ; sc, scapula. Scale bars, $1 \mathrm{~cm}$. 
hypapophyses in the midventral anterior region, and presenting variably developed midventral longitudinal keels. In PULR 08, cervical vertebrae 3 and 4 lack keels, but cervicals $5-8$ have faint ones like the 'Series 1' of MCZ 4118; in contrast,
PVL 4597 has only a very subtle keel in cervical 8 and lacks them in the remaining vertebrae. This morphology contrasts with the sharp ventral keels present in the cervicals of Erpetosuchus (Benton \& Walker, 2002) and the two mid-cervical vertebrae

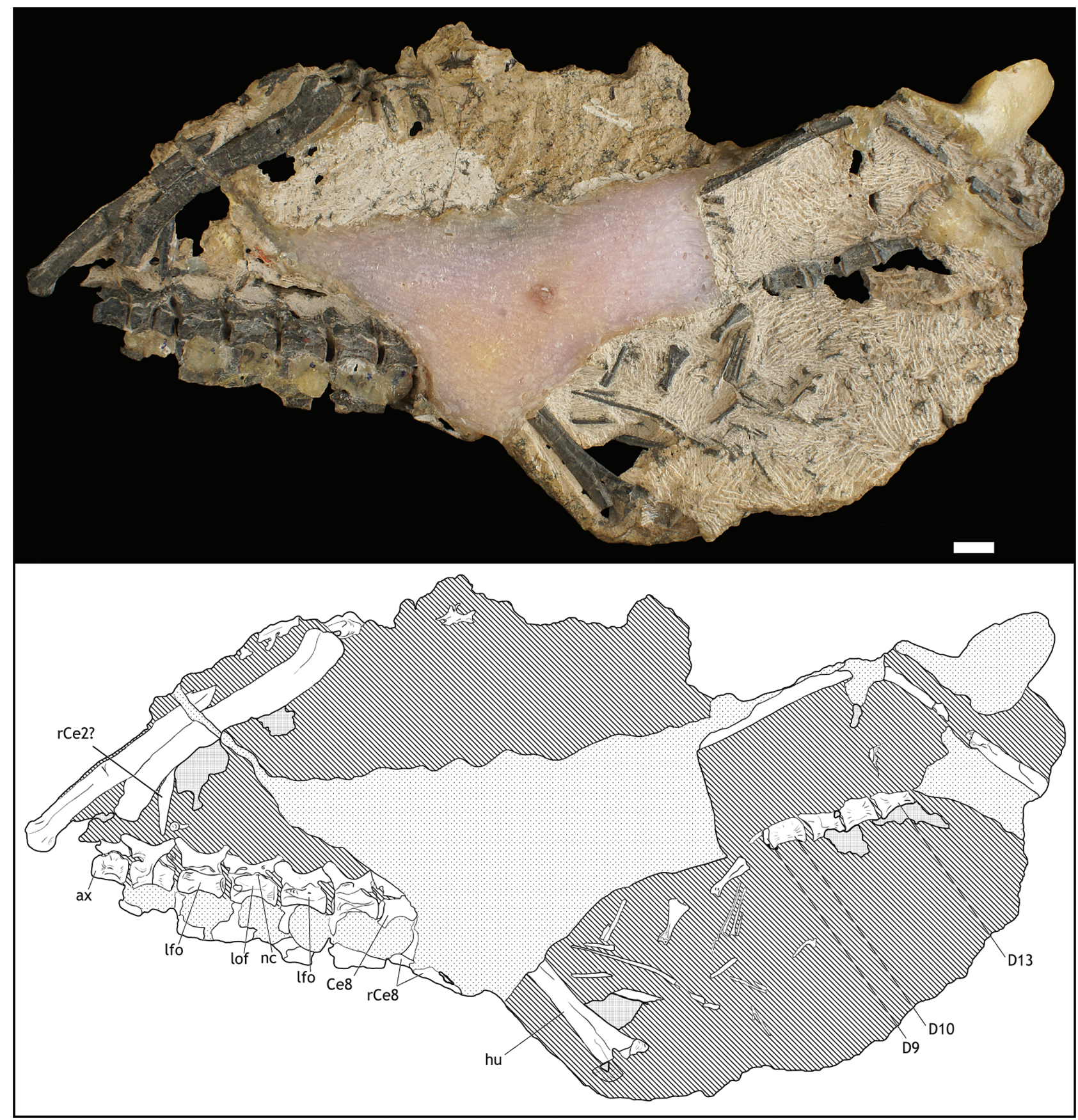

Figure 13. Gracilisuchus stipanicicorum (PULR 08), postcranium in left lateral and ventral view. References in drawings: stripes, sediment; loose spots, glue; dense spots, empty regions. Abbreviations: ax, axis; Ce3-Ce8, cervical vertebrae 3-8; D9-D13, dorsal vertebrae 9-13; hu, humerus; lfo, longitudinal lateral fossa of vertebral centrum; nc, inverted V-shaped notch in vertebral centra; rCe2?, putative cervical ribs 2; rCe3-rCe8, cervical ribs 3-8; rD1-rD12, dorsal ribs 1-12; S1, sacral vertebra 1 . Scale bars, $1 \mathrm{~cm}$. 

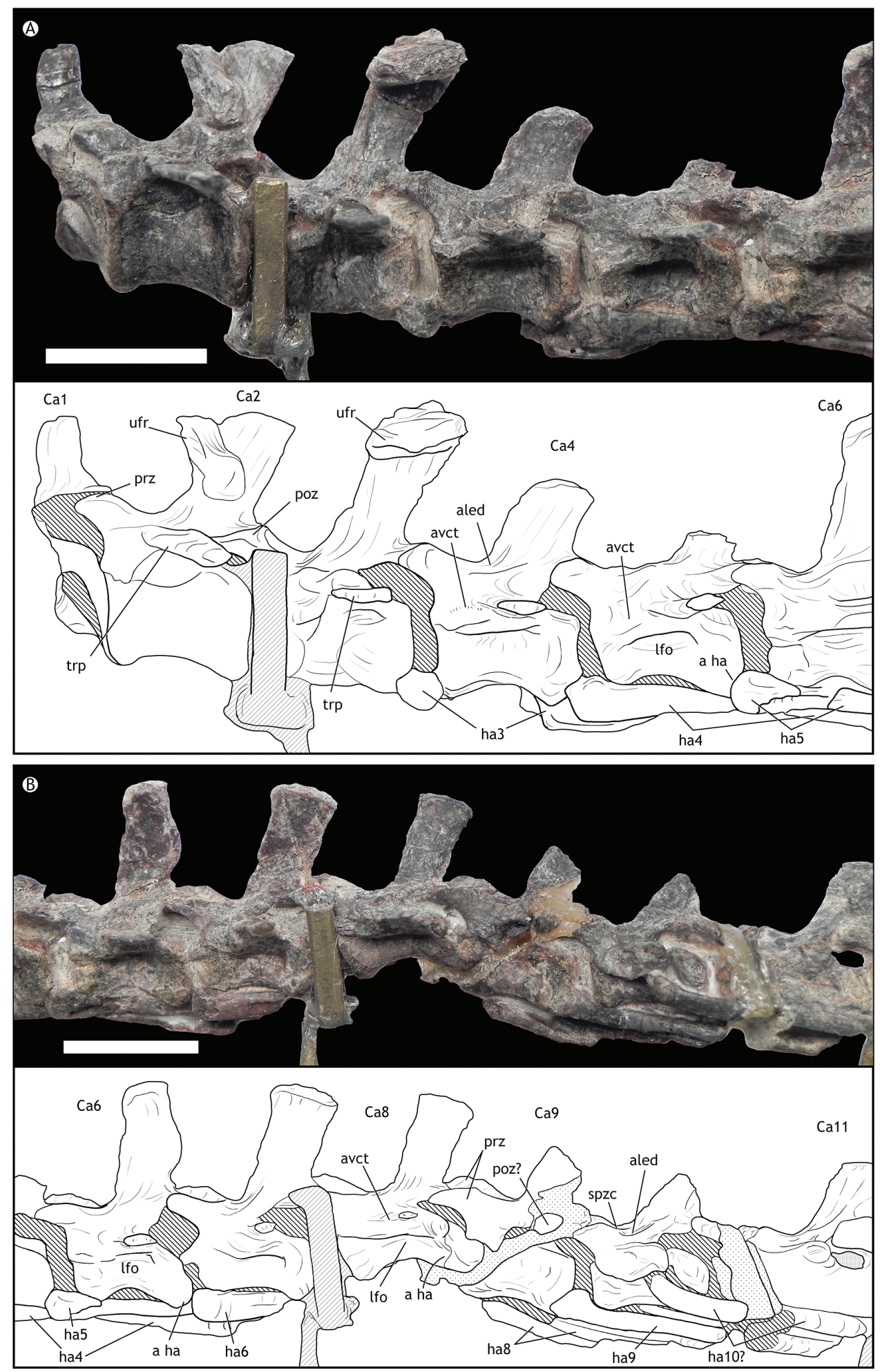

Figure 14. Gracilisuchus stipanicicorum (PVL 4597), caudal series in left lateral view from first to sixth vertebrae (A) and from sixth to $11^{\text {th }}$ vertebrae (B). References in drawings: stripes, sediment; loose spots, glue; dense spots, empty regions. Abbreviations: a ha, articular facet for haemal arches; aled, anterolateral elongated depression in caudal vertebrae; avct, anteroventral concavity to transverse process; Ca1-Ca11, caudal vertebrae 1-16; ha3-ha10, haemal arches 3-10; lfo, longitudinal lateral fossa of vertebral centrum; poz, postzygapophysis; prz, prezygapophysis; spzc, supraprezygapophyseal crest of caudal vertebrae; trp, transverse process; ufr, undetermined fragment. Scale bar, $1 \mathrm{~cm}$. 

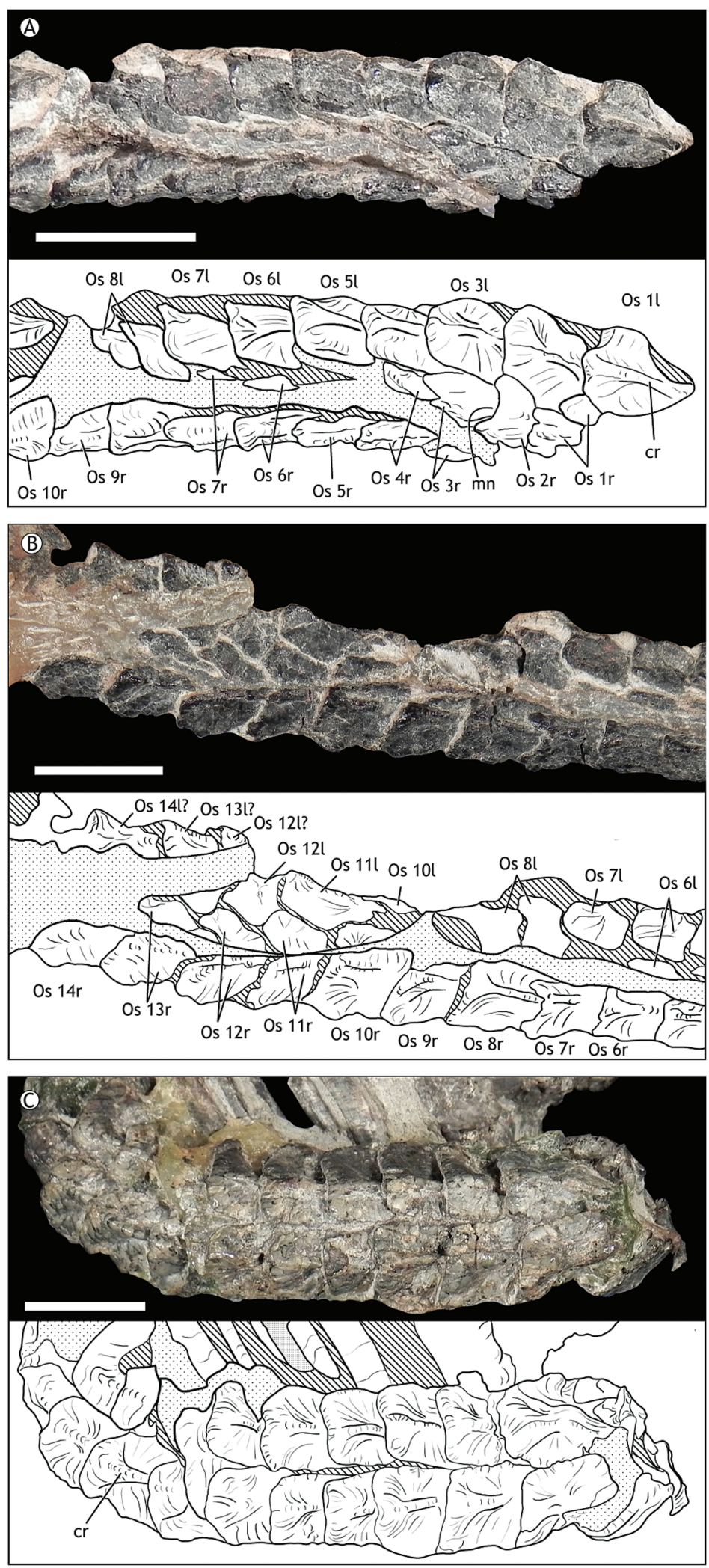

Figure 15. Gracilisuchus stipanicicorum paramedial osteoderms. Anterior cervical series of PULR 08 (A); posterior cervical series of PULR 08 (B); dorsal series of PVL 4597 (C). References in drawings: stripes, sediment; loose spots, glue; dense spots, empty regions. Abbreviations: cr, crest; mn, median notch on the osteoderms; Os 1-141, left osteoderms 1-14; Os 1-14r, right osteoderms 1-14. Scale bar, $1 \mathrm{~cm}$. 

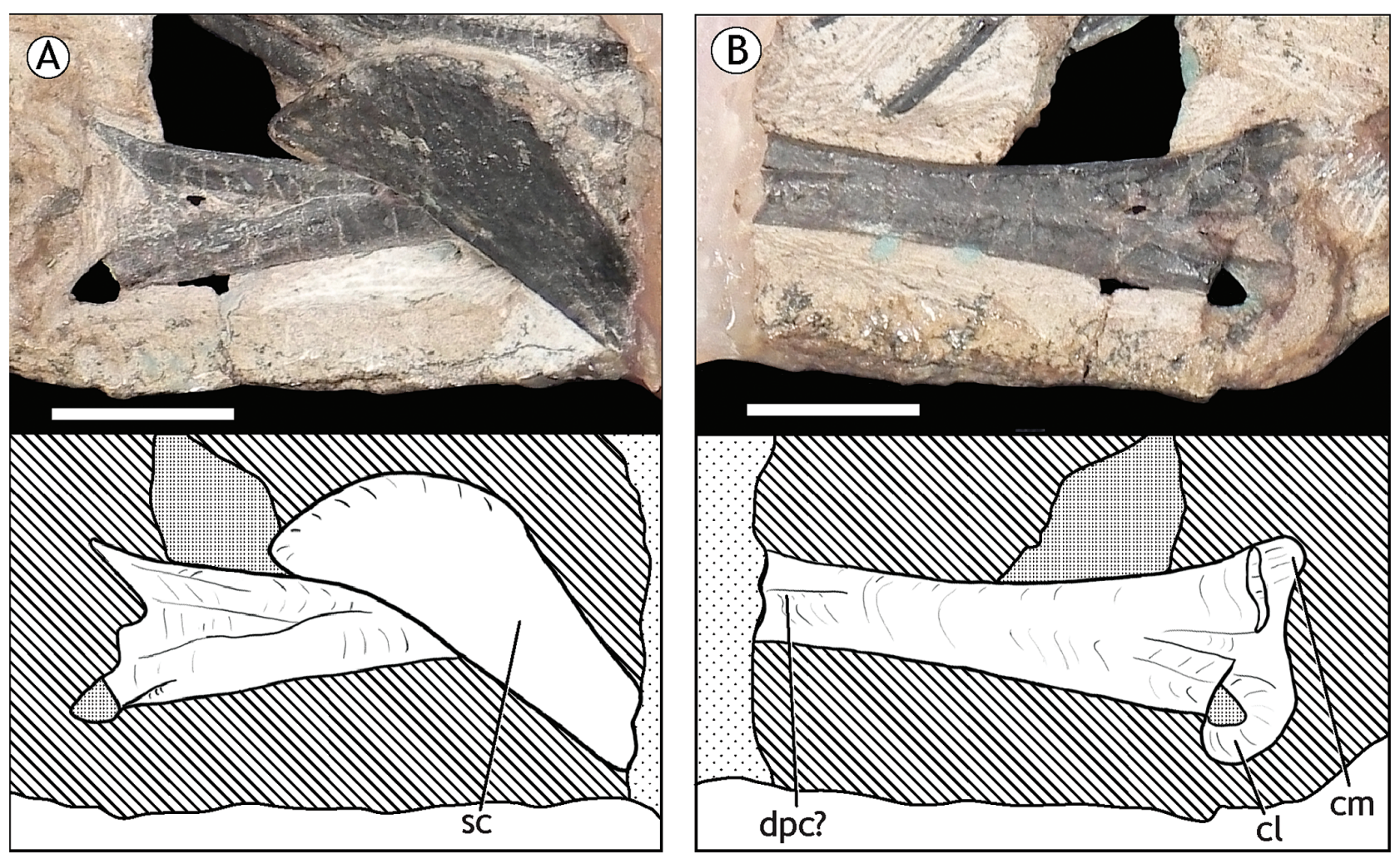

Figure 16. Gracilisuchus stipanicicorum (PULR 08), distal end of right humerus and scapula in posterior view of the humerus (A) and anterior view of the humerus (B). References in drawings: stripes, sediment; loose spots, glue; dense spots, empty regions. Abbreviations: cl, lateral condyle of humerus; $\mathrm{cm}$, medial condyle of humerus; dpc?, putative deltopectoral crest; sc, scapula. Scale bars, $1 \mathrm{~cm}$.

preserved in Nundasuchus songeaensis Nesbitt et al., 2014, the keels present in Euparkeria (Ewer, 1965) that are more developed in the anterior region of the series, the keels of the aetosaurs Aetosauroides scagliai (PVL 2059) and Stagonolepis (Walker, 1961), 'rauisuchians' (e.g. Saurosuchus, PVSJ 32), and those that are very well developed in ornithosuchids (e.g. Riojasuchus, PVL 3827), among others. The lateral surfaces of the vertebral centra have a longitudinal fossa extended along their entire anteroposterior length. They are dorsoventrally low and shallow in PULR 08 and MCZ 4118, but deeper in PVL 4597. Such a longitudinal fossa is also present in other suchians, such as Turfanosuchus, aetosaurs (e.g. Aetosauroides, Stagonolepis), 'rauisuchians' (e.g. Batrachotomus) and Ticinosuchus, which present a smaller fossa in the middle of the centrum. The anterior articular facets of the cervical verterbrae are flat to concave (not seen in MCZ 4118). The posterior articular facets have a double curvature, where the dorsal half is concave and the ventral one is convex in most vertebrae where the facet is exposed, such as vertebrae $3-5$ of PULR 08 and vertebra 4 of PVL 4597 (Tables S1 and S2); however, flat posterior facets are present in vertebrae 3 and 7 of PVL 4597 (not exposed in MCZ 4118) (Figs 7-9).

The neural spines of the cervical vertebrae are anteriorly inclined (both anterior and posterior borders), considering the anterior border of the neural spine with respect to the longitudinal axis of the vertebrae. In the holotype (PULR 08), cervical vertebra 3 is the least inclined (the most vertical; Table S1) and cervical vertebra 7 is the most inclined. In PVL 4597 only cervical vertebrae 4, 6 and 7 are visible in order to measure their inclination, and it is possible to recognize that their spines are less inclined than in the holotype (Table S1). The cervical neural spines are both higher and anteroposteriorly longer in PVL 4597 than in PULR 08 in absolute terms (Table S1), which can be related to the generally larger size of the specimen. The dorsal end of the neural spines has spine tables in a few of the exposed vertebrae, such as in cervical vertebra 4 of PVL 4597 and 6 and 7 of MCZ 4118 'Series 1' (Romer, 1972a). In other elements the structure is not seen due to erosion or presence of sediment. The spine table is poorly laterally projected and slightly more developed in MCZ 4118 than in the other specimens, and shows a smooth transition from 
the vertical body of the neural spine to the horizontal dorsal table. The presence of similar spine tables are seen in the preserved cervicals of Turfanosuchus (IVPP V3237) and Euparkeria (Ewer, 1965), but contrasting with the T-shaped cervical neural spines of the suchians Nundasuchus songaensis (Nesbitt et al., 2014), with a diamond-shaped spine table; and cervical 3 of Ticinosuchus ferox, where the distal end of the neural spine is incipiently laterally projected and more developed in the posterior region (PIMUZ T2817, photographs provided by M. Ezcurra). A shallow anterolateral depression on the anteroventral region of the neural spine is present in some vertebrae of Gracilisuchus, forming a thin neural spine at the base and a step-like contact with the rest of the neural arch. In other vertebrae, this depression is located at the dorsal region of the neural arch, but no pattern of variation is seen between these two morphologies along the series. The anterolateral depression is seen in all cervical vertebrae of the holotype, PVL 4597 and MCZ 4118 specimens. This depression is also seen in some cervicals of Turfanosuchus, such as presacrals 6 and 8 , but located more dorsally in the neural spine than in Gracilisuchus. In the holotype vertebrae 4-8, the anterolateral depression continues posterodorsally onto the neural spine in a short posterodorsal groove (Fig. 7).

The prezygapophyses are orientated anterolaterally and slightly dorsally. The 4 and 7 th cervical vertebrae of PULR 08 and the 4th cervical of PVL 4597 have an almost horizontal prezygapophysis, but that of the 7th cervical vertebrae of PVL 4597 is anterodorsally orientated, with almost no lateral component. Most prezygapophyses project entirely anterior to the centrum (Fig. 7B), with the exception of those of the 8th cervical vertebrae of both specimens that remain posterior to the anterior border. The same is true for cervical vertebra 3 of Turfanosuchus (IVPP V3237), but the posterior preserved cervicals are just short and anteriorly projected; in Erpetosuchus the prezygapophyses are short and apparently completely projected anterior to the centrum (Benton \& Walker, 2002: fig. 3A); the prezygapophysis of the?sixth cervical vertebra of the aetosaur Stagonolepis (Walker, 1961: fig. $7 \mathrm{~g}$ ) is very short anterior to the centrum. The prezygapophyses are located at the same height or slightly dorsal to the postzygapophyses, except in PVL 4597 cervical vertebra 8, which is more dorsally located. The zygapophyses are also located at the same height in Turfanosuchus (IVPP V3237), Erpetosuchus (Benton \& Walker, 2002) and the ornithosuchid Ornithosuchus (Walker, 1964: fig. 8c) but the prezygapophysis is lower than the postzygapophysis in cervical ?6 of Stagonolepis (Walker, 1961: fig. 7g). The prezygapophyses are shorter in PULR 08 than in PVL 4597
(Table S1), probably due to the former's overall smaller size. The postzygapophyses are posterolaterally projected from the posteroventral end of the neural spine, where the postzygapophyseal facets are located in its posterior end and orientated mostly ventrally, except in the 4 th cervical vertebrae of PULR 08 and the 8 th of PVL 4597 that are laterally orientated. The dorsal surface of the postzygapophyses continues smoothly with the posterior margin of the neural spine, showing a variable profile in lateral view among vertebrae and specimens, being slightly convex, straight or concave. A somewhat straight or slightly convex dorsal margin in lateral view is observed in Turfanosuchus, but this margin is more convex in Aetosauroides scagliai Casamiquela, 1960 (PVL 2059). The postzygapophyseal facet of cervical vertebra 3 of PULR 08 occupies a large part of the total extension of the postzygapophyseal pedicle (70\%, Table S1). An infrapostzygapophyseal depression is located on the proximoventral region of the postzygapophysis, in the contact with the neural arch (Figs 7A, 8). This is a small, rather longitudinally elongated concavity that opens ventrally and continues posteriorly as a shallow groove on the ventral surface of the postzygapophysis. The infrapostzygapophyseal depression is deeper in the holotype than in PVL 4597 and MCZ 4118 ('Series 1'), probably due to ontogenetic variation. The infrapostzygapophyseal depression in the cervical vertebrae of Gracilisuchus contrasts with the infrapostzygapophyseal fossa present in several 'rauisuchians' such as Stagonosuchus nyassicus von Huene, 1938 (GPIT RE 3831) and Batrachotomus kupferzellensis Gower, 1999. The former taxon has a deeper and larger dorsoventral fossa that extends onto the posterior surface of the diapophysis; and the latter taxon has longitudinal fossae ventral to the postzygapophyseal facet that are shallow in the anterior cervical vertebrae (e.g. SMNS 80285, SMNS 80286) but deeper in the middle and posterior vertebrae (e.g. SMNS 80289, SMNS 80290, SMNS 80291, SMNS 80292), not reaching the articular facet of the postzygapophysis. The infrapostzygapophyseal depression seen in Gracilisuchus is absent elsewhere within Archosauria, such as in Turfanosuchus, Stagonolepis, Aetosauroides and Ornithosuchus.

The neurocentral suture in most vertebrae of PULR 08 is variably fused along the vertebra, showing a fused middle region and opened anterior and posterior ends; an exception is seen in cervical vertebra 6 , whose neurocentral suture is almost fused up to both ends. Conversely, a complete anteroposterior fusion is observed in the vertebrae of PVL 4597 and MCZ 4118. Posterior to the diapophysis the inverted V-shaped notch of the neurocentral suture is seen projecting from the centrum into the neural arch (Figs 7B, 8) in cervical vertebrae $3-6$ and progressively decreases in 
height backwards in the series (PULR 08, PVL 4597, MCZ 4118). In cervical vertebra 7 the notch is only seen on the right side of the holotype. The diapophysis of cervical vertebra 3 of the holotype is represented by a long, low and flat diapophyseal facet located on the anterior half of the vertebra (Fig. 7B), but in PVL 4597 the articular facet of cervical 3 is subcircular and ventrally orientated at the end of a short diapophyseal peduncle. From vertebra 4 and posteriorly, the diapophyseal peduncles are short and ventrolaterally orientated, except in the 8th cervical of PULR 08 and PVL 4597 where they are anteroventrally orientated. In all the cervical vertebrae of Gracilisuchus, the diapophyses are located ventrally in the neural arch, but in the left side of cervical 4 of the holotype, a small bump is located in the dorsal region of the vertebral centrum, below the portion of the diapophysis located in the neural arch, suggesting that this diapophysis could be partially in the centrum.

The parapophyses are represented by small facets in the anteroventral surface of the centrum, lacking a parapophyseal peduncle. This facet is small and circular in the 3rd vertebra of PURL 08 and PVL 4597 (Figs $7 \mathrm{~B}, 8,10$ ), but very slightly posterodorsally elongated in MCZ 4118. From vertebra 5 the facet continues posteriorly into a longitudinal ridge that variably reaches the middle of the centrum or nearly contacts the posterior end of the centrum in PULR 08 and PVL 4597. This longitudinal ridge is observed in basal suchians such as Nundasuchus (Nesbitt et al., 2014) and some 'rauisuchians' (e.g. Batrachotomus, SMNS 80288, SMNS 80291) but is absent (e.g. Postosuchus kirkpatricki, Weinbaum, 2013; P. alisonae, NCSM 13731) and undetermined in others (e.g. Turfanosuchus, IVPP V3237; Erpetosuchus, Benton \& Walker, 2002). The parapophyseal facets of the last two cervicals of PULR 08 are triangular with the apex posteriorly directed and continuing as a longitudinal crest. The parapophysis and its posterior longitudinal crest define a ventral parapophyseal fossa and separate it from the lateral longitudinal fossa in the middle of the vertebral centrum.

Dorsal vertebrae: When combining the three specimens of Gracilisuchus (PULR 08, PVL 4597 and MCZ 4118), almost all dorsal vertebrae are preserved, from dorsal vertebra 3 to 16 , which is the last dorsal. The dorsal vertebra 9-16 are preserved in the holotype, exposed in lateral aspect (Figs 12, 13); in PVL 4597, dorsal vertebrae $3-5$ are incompletely preserved and partially covered with sediment, vertebrae 6-13 are better preserved (Figs 10, 11), and vertebrae 15 and 16 are well preserved in articulation with the sacral vertebrae; in MCZ 4118, a series of six anterior dorsal centra ('Series 2') and nine middle to posterior dorsal vertebrae ('Series 5') are preserved, but it is not possible to determine their precise position in the cervicodorsal region. The vertebral centra are quite symmetric, being strongly to more faintly spool-shaped. A longitudinal fossa is present on the lateral surface of most of the dorsal vertebrae, varying among vertebrae and specimens in their length, height and depth. These differences suggest not only a natural variation but some post mortem deformation. The anterior and posterior articular surfaces are flat to concave (Table S4), differing from the double curvature present in the cervical vertebrae, but resembling the morphology seen in other archosaurs such as the amphicoelous dorsals of Parringtonia gracilis Huene, 1939 (Nesbitt \& Butler, 2012) and Nundasuchus (Nesbitt et al., 2014), among others. A ventral very faint keel is only seen in dorsal 9 of PVL 4597, this specimen lacking such a structure in the remaining exposed vertebrae. The general absence of such structures is similar to the aetosaurs Aetosauroides scagliai (PVL 2073) and Stagonolepis robertsoni (Walker, 1961: fig. 8c), but contrasts with the presence of marked ventral keels in the ornithosuchid Riojasuchus (PVL 3827) and the erpetosuchid Erpetosuchus (Benton \& Walker, 2002), with the weak ones in Parringtonia (Nesbitt \& Butler, 2012), and the presence of two paramedian ridges and a mid-line fossa in Nundasuchus (Nesbitt et al., 2014). The neural spines of PVL 4597 are similar to each other, but range from 29 to $52 \%$ of the total vertebral height (Table S4). The neural spines are located at the level of the posterior half of the centrum where the anterior border of the spine is located in the centre of the neural arch. No spine tables are observed in the preserved dorsal neural spines (Figs 10,12), contrasting with their presence in the gracilisuchid Turfanosuchus dabanensis, the preserved anterior dorsal vertebrae of the erpetosuchids Erpetosuchus (vertebrae 8-10; Benton \& Walker, 2002) and Parringtonia (Nesbitt \& Butler, 2012), the preserved dorsals of the aetosaurs Stagonolepis and Aetosauroides, as well as the anterior or mid-dorsals of the basal suchians Nundasuchus and Ticinosuchus. In the anteroventral region of the neural spine, near the contact with the rest of the neural arch, an anterolateral depression can be seen, shallower in the dorsal vertebrae than in the cervical vertebrae. PULR 08 possesses depressions larger in area that can be seen up to dorsal vertebra 13 (unpreserved posteriorly), whereas PVL 4597 has smaller and punctual depressions that can only be tracked posteriorly up to the dorsal 10 , and posteriorly the vertebrae show an almost right angle contact between the neural spine and the rest of the neural arch.

The prezygapophyses are short, anterolaterally projected processes, horizontally orientated in dorsal vertebrae 6,7 and 12 , but somewhat dorsally orientated in the remaining vertebrae. The prezygapophyses are at the same height as the postzygapophyses 
of the same vertebra in vertebrae $10,11,15$ and 16 of PVL 4597, whereas in dorsal vertebra16 of PULR 08 the prezygapophysis is ventral to the postzygapophysis (in the other vertebrae of this specimen, the condition cannot be determined) (Figs 10-13). The anterior end of the prezygapophyses is located anterior to the anterior articular facet of the centrum in most vertebrae preserved (vertebrae 10, 11 and 12 of PULR 08; vertebrae 12, 15 and 16 of PVL 4597) but two vertebrae of PURL 08 have the prezygapophyses at the same level as the anterior articular facet (vertebrae 13 and 16). This variation is probably due to some post mortem deformation. The presence of prezygapophyses at the same level as the anterior border of the centrum is seen in Turfanosuchus, Parringtonia and Nundasuchus; conversely, slightly more anterior prezygapophyses than the anterior margin of centrum are present in Euparkeria (Ewer, 1965). The postzygapophyses of most vertebrae are developed as facets located in the ventrolateral end of the neural spine, lacking a clear postzygapophyseal peduncle, and consequently the posterior surface of the postzygapophysis forms a continuous concave border in lateral view with the posterior surface of the neural spine. The posterior ends of the postzygapophyses extend posteriorly to the posterior articular facet of the centrum in dorsal vertebrae 11 and 12 of PULR 08 and PVL 4597, and vertebra 16 of PVL 4597.

The neurocentral suture is not well exposed in any preserved vertebrae of PULR 08 and PVL 4597. The first specimen has very faint or almost obliterated sutures in the exposed vertebrae (10, 11 and 13); whereas PVL 4597 has no visible sutures, except a slight one in dorsal 10. The diapophyses and parapophyses are developed as separated processes or facets up to the eighth dorsal vertebra, whereas from the ninth they are located in the transverse process. Dorsal vertebrae 4 and 5 of PVL 4597 have long and posterolaterally orientated diapophyses that are located at the same height as the prezygapophyses, and the parapophyses are short projections in the anteroventral surface of the diapophyses. In vertebrae $6-8$ of the same specimen, the diapophyses are short, posterolaterally projected, horizontal and located at the same height as their respective prezygapophyses. In vertebrae 6 and 7 the parapophyses are short processes located on the anteroventral region and projected posteroventrally. In PULR 08, the ninth vertebra shows that both the parapophysis and the diapophysis are poorly developed in the anterior and posterior surfaces of a transverse process. These processes are horizontal, posterolaterally projected and located at level with the postzygapophysis (Fig. 12). Posteriorly in the dorsal series, the transverse process is developed as a thin diagonal lamina arising from the anteroventral region of the neural arch and directed posterodorsally up to the middle of the arch. The posterodorsal inclination of this process is variable among the vertebrae. The parapophyseal and diapophyseal articular facets are poorly developed. A somewhat deep cavity is recognized under the transverse process in vertebra 16 of PULR 08 and PVL 4597, and in the right side of vertebra 15 of PVL 4597. This cavity resembles the one present in presacrals 18 and 19 of another gracilisuchid, Turfanosuchus, but contrasts with the much more developed and deeper centrodiapophyseal fossa present in the anterior dorsals of other derived suchians (e.g. Nundasuchus, Nesbitt et al., 2014; Batrachotomus, SMNS 80296, SMNS 80297, SMNS 80319; Stagonosuchus nyassicus, GPIT RE 3831).

Sacral vertebrae: These vertebrae are available in specimens PULR 08 and PVL 4597; in the former only a poorly preserved first sacral is preserved, and the latter specimen has a well-preserved first vertebra and almost complete second sacral vertebra, which has lost a short posterior region of the centrum.

The first sacral vertebra shows the complete neural spine in the holotype specimen, but is distally broken in PVL 4597 (Tables S3, S4). The neural spine is located in the posterior half of the neural arch and it lacks a spine table in the distal end. The vertebral centrum is spool-shaped, presenting a circular lateral depression posterior to the contact with the transverse process, probably representing a shortened condition of the longitudinal lateral fossa present in the presacral vertebrae. The prezygapophysis is located anterior to the base of the neural spine and projects anterodorsally in a parasagittal plane. The prezygapophyseal facet faces dorsomedially and projects slightly anterior to the anterior border of the centrum. The postzygapophysis is better observed in PVL 4597, which possesses a straight dorsal surface and it is almost horizontal in lateral view and somewhat laterally orientated in posterior aspect. The posterior end of the postzygapophysis does not exceed the level of the posterior end of the centrum. The transverse processes are almost fused to the ribs where the suture is barely seen close to the base of the process. The dorsal surface of the process is located in the dorsal border of the neural arch, forming a long shelf that extends the full anteroposterior length of the arch. The ventral portion of the transverse process is a more rod-like structure, anteroposteriorly short, occupying less than half the anterior portion of the vertebrae, and with its ventral border located at mid-height of the centrum. The dorsal shelf-like portion and the narrow ventral rod-like transverse process are separated in the anterior and posterior surfaces by a pair of long longitudinal grooves. The anterior groove is shallow but the posterior one is deep, thus forming an acute angle between both dorsal and ventral portions. The depth of these grooves is similar in Turfanosuchus, 
but apparently the anterior groove of Nundasuchus is deeper (Nesbitt et al., 2014: fig. 4L). In dorsal view, the anterior and posterior edges are concave due to the distal expansion of the rib for the contact with the ilium. In the holotype this lateral expansion represents $70 \%$ of the length of the process, whereas in PVL 4597 the expansion is shorter (Table S3). The articular facet for the ilium is subquadrangular in outline, where the dorsal region is longer than the ventral one. This articular surface is ventromedially inclined with the dorsal region contacting the ventral iliac blade and the ventral portion of the facet contacting the dorsal region of the acetabulum.

The second sacral vertebra is only preserved in PVL 4597 , missing the posterior region of the centrum, the postzygapophyses and the distal end of the neural spine. The vertebral centrum has a shallow lateral depression below the transverse process, and is transversely narrow ventrally in the middle of the centrum. The neural canal is somewhat diamondshaped and larger than the centrum in transverse section. The prezygapophyses are long and narrow, anterolaterally projected from the anterior border of the neural spine, and reach anteriorly the level of the posterior border of the neural arch of the first sacral vertebra. The dorsal surface of the neural arch has an elongated depression extended from the base of the neural spine and directed anteroventrally to a point between the transverse process and the prezygapophysis. A depression apparently similar in position is found in Turfanosuchus (IVPP V3237) but contrasts with the dorsally opening fossa of Nundasuchus, which is laterally limited by a lamina (Nesbitt et al., 2014). The transverse process is high at its base, extending from the dorsal surface of the neural arch down to the middle of the centrum. The ventral end of the process is anteroposteriorly longer in this vertebra than in the first sacral. The anterior surface of this whole structure (transverse process + sacral rib) is higher than the posterior surface and also possesses a longitudinal groove as in the first sacral. The suture between the transverse process and the rib is close to the centrum (approximately 0.2 times the total length of the whole structure). The rib flares transversally towards its distal end to contact the ilium, where the posterior expansion contacts the dorsal surface of the medial brevis shelf and the smaller anterior expansion reaches the posterior border of the acetabular region. This lateral expansion is larger than in the first sacral rib, as in Euparkeria, Turfanosuchus and Saurosuchus, but contrasting with Nundasuchus, where the second sacral rib is less expanded than the first one. The distal ends of the first and second sacral ribs of Gracilisuchus are slighty damaged, but as they are preserved it can be deduced that they did not contact each other. This lack of contact is also present in other basal taxa (e.g. Euparkeria), but contrasts with other taxa where the ribs contact each other, such as aetosaurs (e.g. Stagonolepis, Walker, 1961) and loricatans (e.g. Batrachotomus, SMNS 80310; Saurosuchus, PVSJ 615) (condition uncertain in Nundasuchus).

Caudal vertebrae: This vertebral series is well preserved in PVL 4597, where the posterior portion of the first caudal and the subsequent 15 complete vertebrae are preserved in articulation (Fig. 14). Among the remains of MCZ 4118, a vertebral series was originally interpreted as caudal ('Series 7'), but here no diagnostic characters have been found with the homologous bones of PVL 4597, so it is not considered in the present description.

The vertebral centra of Gracilisuchus are spoolshaped in ventral view, like in the presacral and sacral vertebral series, but more ventrally concave in lateral view than in the more anterior elements. The ventral surface is smooth without a keel in the caudal vertebrae where this surface is exposed (caudals $2-4,8$ and 12-16). Caudal 2 is rounded ventrally, but from caudal 3 and posteriorly, it is slightly flat with a shallow median depression posteriorly, just anterior to the facet for the haemal arches. This morphology contrasts with that of Parringtonia, which has two ventrolateral ridges in the anterior caudals and an additional midline keel in the posterior caudal, with some vertebrae of Batrachotomus that present a median logitudinal fossa (e.g. SMNS 80330, SMNS 80332, SMNS 80339), as well as Aetosauroides that also have a median fossa and an additional median faint keel in some caudals (PVL 2073); no other more closely related taxa could be compared. The lateral surface of the caudals of Gracilisuchus is also concave but does not show a longitudinal lateral fossa, contrasting with the anterior vertebral series of the species. The first and second caudals lack articular facets for the haemal arches, and from vertebra 3 and posteriorly, a posteroventrally directed small flat facet for articulation with these elements is present.

The neural spines are well preserved in most caudal vertebrae, being approximately as high as the rest of the neural arch plus the centrum in the anterior vertebrae, and slightly increasing this proportion backwards in the series (Table S5). The neural spines are posteriorly inclined, ranging from $95^{\circ}$ to $129^{\circ}$ in the 6 th and 15 th vertebra, respectively, where the angle is measured from the anterior edge of the spine to the longitudinal axis of the vertebra (Table S5). The anteroposterior extension of the neural spine is somewhat constant through its complete length, with the exception of caudal 6 that has a short posterior projection 
(Fig. 14B). The anterior edge is straight in lateral view and very thin, thus forming an acute apex in transverse section. The neural spines of the preserved vertebrae lack an accessory laminar process ('accessory neural spine', Crush, 1984) in their anterior edges. This structure is also absent in some basal archosauriforms (e.g. Euparkeria, Ewer, 1965) and the gracilisuchid Turfanosuchus (IVPP V3237), and it is unknown in Erpetosuchidae (Erpetosuchus and Parringtonia). Conversely, other basal archosaurs possess accessory neural spines generally in the middle to posterior caudal vertebrae, such as the phytosaur Smilosuchus gregorii (USMN 18313), ornithosuchids (Riojasuchus, PVL 3827; Ornithosuchus, Walker, 1964) and more widely distributed among 'rauisuchians', such as Ticinosuchus ferox (Lautenschlager \& Desojo, 2011), Qianosuchus mixtus (Li et al., 2006), Batrachotomus kupferzellensis (SMNS 80339), and in the basal crocodylomorphs Terrestrisuchus gracilis Crush, 1984 and Pseudhesperosuchus jachaleri Bonaparte, 1969 (PVL 3830 ). In some vertebrae the dorsal tip is slightly longer and wider than the rest of the spine but it is not considered a spine table (e.g. vertebrae 2 , and 6-8); the other vertebrae lack this enlargement, which is interpreted here as an intervertebral variation. The absence of spine tables in Gracilisuchus contrasts with the condition in Turfanosuchus (IVPP V3237), which has a very faint distal expansion in the preserved caudal neural spines (caudals 4 and 5), as well as in Parringtonia (Nesbitt \& Butler, 2012), which has a longitudinal median pit with lateral rims. The neural spine is located in the posterior half of the neural arch, variably occupying the complete or less than the posterior half of the arch in different vertebrae. In the ventralmost anterolateral region of the neural spine, there is an anteriorly elongated narrow depression that reaches the base of the prezygapophyses (Fig. 14A), present in most vertebrae posterior to the third one. This depression is seen in lateral view increasing in length posterior in the series. Posterior to this anterolateral depression and dorsal to the transverse process, there is a somewhat inflated surface on the neural arch.

The prezygapophyses project anterolaterally and slightly dorsally from the dorsal region of the neural arch and lateral to the neural canal. In lateral view, the prezygapophyses of vertebrae $2-8$ are at the same height as the postzygapophyses, but from the $10^{\text {th }}$ posterior the prezygapophyses are slightly lower. The prezygapophyses of caudals 2 and 3 extend shortly anterior to the anterior articular facet of the centrum, whereas posterior to the 4 th caudal the anterior extension is longer. Caudal vertebra 10 shows a very low supraprezygapophyseal ridge extending from the base of the spine to the middle dorsal surface of the left prezygapophysis, not seen on the right side (Fig. 14B). The postzygapophyses project posterolaterally from the posterior border of the neural spine, being depressed and showing a concave or straight dorsal border in lateral view (Figs 14, S4). They are short processes extending slightly posterior to the posterior articular facet of the centrum and dorsal to the neural canal. The ventral border of the postzygapophyses continues in semicircular outline in lateral view with the posterior edge of the neural arch and the dorsal part of the centrum; this region is short and low in the first seven vertebrae, but becomes longer and taller posterior in the series. From the lateral anteroventral corner of the postzygapophysis, a faint ridge borders the neural canal orientated towards the transverse process, being more pronounced in caudal vertebrae 4, 5, 7 and 8 . No infrapostzygapophyseal depression is seen below the postzygapophyses.

The transverse processes are located ventrally in the posterior region of the neural arch, occupying approximately half of its anteroposterior length (Figs 14, S5). The transverse process of the second caudal vertebra is considerably longer anteroposteriorly than in more posterior elements. Additionally, the ventral surface of the transverse process is slightly concave, showing an anteroventral and a posteroventral ridge directed to the anterior and posterior dorsal corners of the centrum. From the 3rd vertebra posteriorly, the ventral surface of the process is variably convex or flat and with less distinct or absent ridges. The length of the transverse processes cannot be measured accurately due to incomplete preservation in most of them and their complete loss in others (Table S5).

Cervical ribs: These elements are preserved in PULR 08, PVL 4597 and MCZ 4118. Six incomplete right ribs, from vertebra 3 to 8 , are preserved in the holotype specimen (Figs 7, 12, 13); PVL 4597 has several incomplete right ribs (Figs 10, 11), and MCZ 4118 has some cervical ribs in 'Series 1 '.

A probable axial rib is preserved disarticulated in PULR 08 below the femora of another specimen (Fig. 13). The exposed portion of the rib corresponds to the proximal region showing the articular processes for the vertebra. The capitulum is wide and laterally directed, whereas the tuberculum is narrow and located in the same axis as the shaft of the rib. The posterior cervical ribs have straight to slightly concave shafts in lateral view, being almost parallel to the vertebral axis. The posteriorly directed shaft of the ribs shows a longitudinal groove on the dorsal surface, where the shorter anterior process of the inmediate posterior rib contacted for almost half of the posterior shaft. The tuberculum and capitulum are perpendicular to the shaft, the tuberculum is larger than the capitulum 


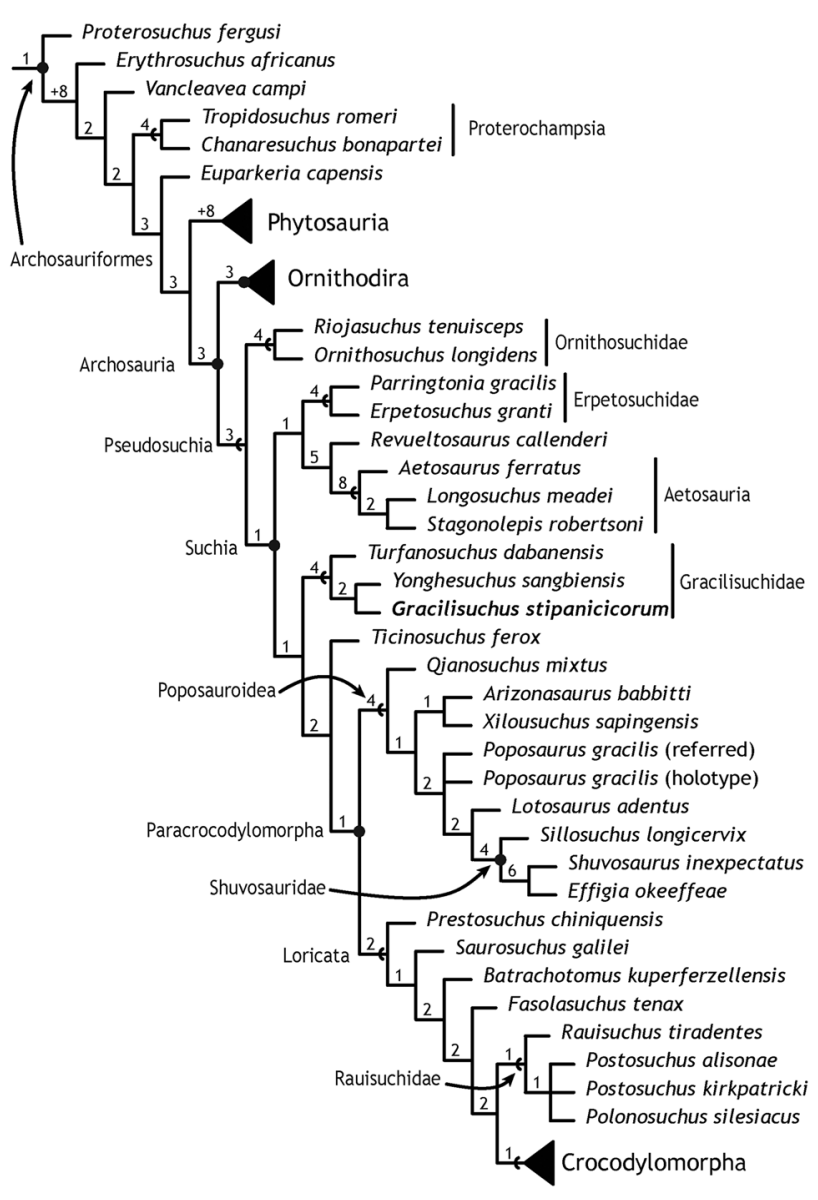

Figure 17. Strict consensus of 32 most parsimonious trees obtained from the phylogenetic analysis of Archosauriformes. The numbers indicate Bremer support values.

up to cervical rib 7 , but in rib 8 the capitulum is the largest. In the latter rib, the tuberculum articular facet is elongated anteroposteriorly and that of the capitulum is circular.

Dorsal ribs: The holotype specimen has incompletely preserved right dorsal ribs, up to dorsal 12 , and two left ribs at the level of dorsal vertebra 10 (Figs 10, 12). In PVL 4597, nine consecutive right dorsal ribs are preserved but disarticulated from their respective vertebrae, so they are of indeterminate position in the series. Another series of seven incomplete consecutive ribs and covered with sediment are also preserved.

The first five right ribs of PULR 08 have lost the proximal region, and from rib 8 posteriorly they have lost the distal end, but all of them preserve their natural position. The ribs are thin and increase in length posteriorly in the series. The first three ribs are straight and posteriorly directed (Figs 12, S2), and from rib 4 and posterior they develop an anteriorly directed swelling in the proximal third. Ribs 6-8 show a proximal articular end with a longer capitulum than a tuberculum, and rib 9 has no articular facets, due to post mortem deformation. Rib 11 has a shorter capitulum than tuberculum, and in rib 12 both articular facets are merged into a single one.

Haemal arches: Haemal arches, or chevrons, are incompletely preserved in PVL 4597. The first remains of an haemal arch are present between caudal vertebrae 3 and 4; the anteriormost two vertebrae lack any sign of haemal arch or articular facet for it (Fig. 14). Posteriorly, the haemal arches are preserved up to caudal 6 , from $8-10$, and 15 . The proximal end of the haemal arches has an anterodorsal and a posterodorsal facet for contact with the posteroventral and anteroventral articular facets of the vertebrae, respectively. These elements are preserved posteriorly directed in contact with the ventral surface of the vertebrae and other haemal arches. Although most elements are incomplete, they are relatively long in the anterior region of the series. Vertebra 4 has a complete and the longest preserved haemal arch, which is nearly three times the length of its respective vertebra (absolute measures in Table S5); the immediate anterior and posterior arches, in vertebrae 3 and 5 , are nearly twice the length of their vertebrae, because in vertebra 3 the haemal arch is hidden by the following one and in vertebra 5 the haemal arch is distally incomplete. In vertebra 6 the haemal arch is very incomplete, and vertebrae 8-10 have nearly complete haemal arches that are more (vertebrae 8 and 9) and less (vertebra 10) than two vertebra long. Finally, the haemal arch of vertebra 15 is distally incomplete, being more than half the length of its respective vertebra.

Osteoderms: Articulated and isolated osteoderms are preserved in several specimens. In the holotype, a partially complete cervical series and several isolated dorsal ones are preserved, being the only specimen that includes articulated anteriormost osteoderms (Fig. 15A, B); in PVL 4597, a cervical series and fragmentary dorsal osteoderms are preserved (Fig. 15C); in MCZ 4117, a single osteoderm is associated with the skull, interpreted as the first osteoderm of the series; and MCZ 4118 has a few articulated osteoderms in 'Series 1 ' and 'Series 5'. The first osteoderm of the holotype is the left element of the first row that is located dorsally to the anterior half of the atlas and axis. Due to the far anterior position of this element, it is hypothesized that in life it was in contact with the posterior region of the cranium.

Gracilisuchus shows a row of paired osteoderms dorsally to the cervical and dorsal vertebrae (Fig. 15). The first element is located dorsal to the axis and the last one is located dorsal to the posterior dorsal vertebrae. 
No osteoderms are associated with the sacral and caudal vertebrae, which could be associated with the absence of spine tables in these regions of the vertebral series, although the presence of these two characters is not always correlated (Nesbitt, 2011: 111). It cannot be definitely assessed if this absence of osteoderms was the natural condition or a preservational artefact.

There are two pairs of osteoderms per vertebrae in the whole cervicodorsal series of Gracilisuchus, as occurs in the gracilisuchid Turfanosuchus (Nesbitt, 2011), in the cervical region of Ticinosuchus ferox (Krebs, 1965), and the paracrocodylomorphs Qianosuchus admixtus (Li et al., 2006) and Saurosuchus galilei (PVSJ 32). In contrast, one pair of paramedian osteoderms over each vertebra is present in Euparkeria capensis (Ewer, 1965), Erpetosuchidae (Erpetosuchus granti, Benton \& Walker, 2002; Parringtonia gracilis, Nesbitt \& Butler, 2012), Ornithosuchidae (Ornithosuchus, Walker, 1964; Riojasuchus, PVL 3827), Aetosauria (e.g. Aetosaurus ferratus Fraas, 1877; Schoch, 2007) and some Paracrocodylomorpha (e.g. the cervical series of Batrachotomus kupferzellensis, MHI 1895; Postosuchus kirkpatricki, Weinbaum, 2013; Dromicosuchus grallator Sues et al., 2003).

Each osteoderm has a side by side contact with its lateral partner in most of the series, but there are some exceptions where the left element is over the right one, probably a post mortem distortion given its scarce presence. Additionally, each osteoderm slightly overlaps the anterior region of the posterior element. The left osteoderm of each row is located slightly anterior to its right counterpart, and thus the posteromedial corner of the right osteoderm slightly overlaps the anterolateral corner of the left element of the immediate posterior row (Fig. 15). This staggered alignment of the osteoderms in Gracilisuchus is also present in Euparkeria (Ewer, 1965), Ticinosuchus ferox (Nesbitt, 2011), Nundasuchus songeaensis (Nesbitt et al., 2014), and the paracrocodylomorphs Qianosuchus mixtus (Nesbitt, 2011), Prestosuchus chiniquensis Huene, 1938 (Nesbitt, 2011) and Saurosuchus galilei (PVSJ 32).

The first osteoderm of the series has a triangular outline, with the apex anteriorly directed, and a welldeveloped longitudinal median crest. In PULR 08 the lateral margin of this element has an anterior notch (Fig. 15A), probably exaggerated by preservation but also present in the isolated osteoderm of MCZ 4117. The latter element is interpreted as the first of the series on the basis of its general shape and welldeveloped median crest. The posterior osteoderms of Gracilisuchus have a leaf-shaped outline, with a short anterior median projection and a posterior subrectangular outline in dorsal view, but the second and third right osteoderms of PULR 08 possess a posterior notch (Fig. 15A) interpreted as probable damage of the material. The presence of an anterior median

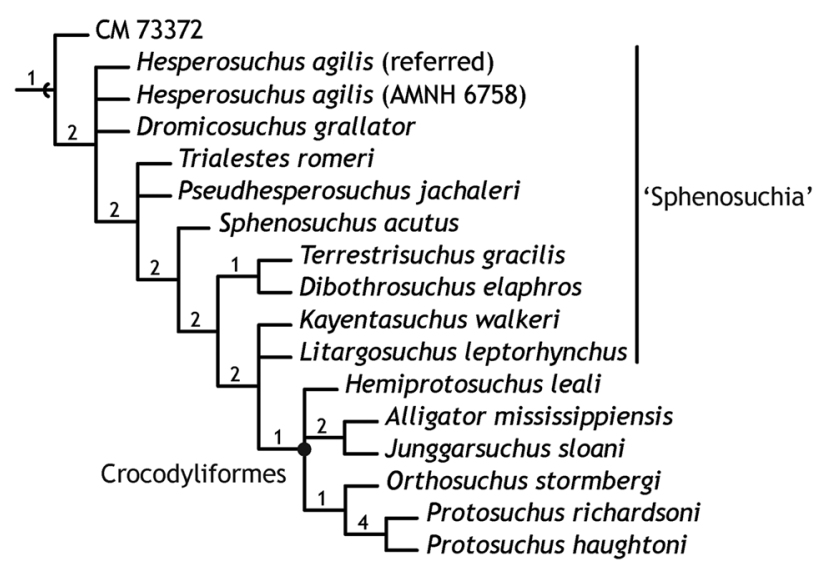

Figure 18. Strict consensus of 32 most parsimonious trees showing the relationships of Crocodylomorpha. The numbers indicate Bremer support values.

projection is seen in taxa such as Euparkeria capensis (Ewer, 1965) and Turfanosuchus dabanensis (Wu \& Russell, 2001), whereas the condition of Gracilisuchus contrasts with more derived suchians. Among the latter, it contrasts with the presence of an anterior projection located somewhat lateral from the median axis, as in Postosuchus alisonae (Peyer et al., 2008), or with the presence of both morphologies along the series as in Batrachotomus kupferzellensis (Gower \& Schoch, 2009; SMNS 90018) and Saurosuchus galilei (PVSJ 32). Additionally, it also contrasts with the absence of an anterior projection in the preserved osteoderms of Parringtonia gracilis (Nesbitt \& Butler, 2012).

The dorsal surfaces of the osteoderms of Gracilisuchus have a longitudinal crest extending from nearly the anterior edge to the posterior one, forming a depression at both sides of the crest in the anteroposterior mid-length. In the posterior third of the osteoderm, the crest rises dorsally and widens, acquiring a triangular outline in dorsal view. This crest is located slightly medially from the centre of the osteoderm (e.g. PULR 08 dorsals, Fig. 15; MCZ 4118 cervicals), but it is also seen in the median line in some osteoderms (e.g. PULR 08 anterior cervicals, Fig. 15). The osteoderms are laterally bent, where the crest defines a dorsally orientated medial surface and a laterally or dorsolaterally orientated lateral surface. The more medial position of the longitudinal crest in Gracilisuchus resembles that of the loricatan Saurosuchus, and some osteoderms of Batrachotomus, but contrasts with the morphology of other osteoderms of the latter species that possess a median ridge. Gracilisuchus also contrasts with taxa where the crest is slightly lateral from the midline, such as Euparkeria (Ewer, 1965), Erpetosuchus (Benton \& Walker, 2002) and Parringtonia (Nesbitt $\&$ Butler, 2012), the rauisuchians P. kirkpartricki and P. alisonae (Weinbaum, 2013; Peyer et al., 2008), as 
well as Turfanosuchus (IVPP V3237), which all possess median ridges.

The osteoderm ornamentation is variably developed, probably due to intraspecific variation, difference in ontogenetic maturity and/or preservational artefacts. The ornamentation of the holotype is mostly smooth with a faint crenulation in the lateral edges and in the medial crest of some elements. PVL 4597 shows striae and grooves radiating from the median crest up to the lateral edge and shallow central depressions to each side of the crest. Posteriorly in the series of this specimen, the striae and grooves are more deeply developed and with crenulated edges. The single osteoderm of MCZ 4117 has a better developed dorsal ornamentation with deeper pits and grooves radiating from the posterior, more elevated region of the crest and from a more central part of the latter, additionally presenting low bumps in the posterior region. A smooth ornamentation similar to PULR 08 is also present in the gracilisuchid Turfanosuchus (IVPP V3237), but a slightly more developed ornamentation with a finely pitted radiating pattern is present in the erpetosuchid Erpetosuchus (Benton \& Walker, 2002), more similar to PVL 4597. The general ornamentation of Gracilisuchus contrasts with another erpetosuchid, Parringtonia (Nesbitt \& Butler, 2012), that possesses deep pits and grooves, but they share a radiating pattern. Gracilisuchus also contrasts with the ornamentation of Batrachotomus, which has small pits and grooves irregularly disposed, with that of $P$. kirkpatricki and P. alisonae, which show fine but defined radiating ridges from the middle region to the edges, and with that of aetosaurs (e.g. Aetosauroides, PVL 2073; Stagonolepis, Walker, 1961), whose ornamentation in the dorsal paramedian osteoderms has deep rounded pits, grooves and ridges that radiate from an eminence located in the posterior region of the osteoderm.

Appendicular skeleton: The appendicular skeleton in G. stipanicicorum is represented by an almost complete hind limb in PVL 4597 (Lecuona \& Desojo, 2011), poorly preserved hind limb elements in MCZ 4118 and a fragmentary forelimb in PULR 08 . The hind limb anatomy of Gracilisuchus has been previously described in detail (Lecuona \& Desojo, 2011) and, as a result, only the elements that unambiguously belong to the forelimb of Gracilisuchus, which have never been described corresponding to the holotype, will be described here. The distal ends of both the right scapula and the humerus are preserved in this specimen (Fig. 16). The scapula has a narrow shaft expanding distally anteroposteriorly more than twice the minimum width of the shaft (Table S9). The anterior expansion is small and rounded in outline, whereas the posterior expansion is longer and tapering to a point.
This morphology contrasts with the symmetric and slight distal expansion of the euparkeriids Euparkeria capensis (Ewer, 1965; SAM-PK-5867, SAM-PK-6048) and Halazhaisuchus qiaoensis Wu, 1982 (Sookias et al., 2014), with the strap-like morphology of Erpetosuchus granti (Benton \& Walker, 2002). Gracilisuchus resembles Turfanosuchus dabanensis (IVPP V3237) and Batrachotomus (SMNS 80274) in being widely expanded distally, but also contrasts because the expansions of the latter two are symmetric. A small and symmetric expansion is present in Ticinosuchus ferox (PIMUZ T2817), contrasting with Gracilisuchus. The crocodylomorph Dromicosuchus (NCSM 13733; Sues et al., 2003) has an asymmetric distal expansion, but it is more developed at its anterior margin, in contrast to Gracilisuchus. A similar morphology is seen in Terrestrisuchus with a pointed posterior distal end and curved anterior one (NHMUK P47/21; Crush, 1984; Allen, 2010).

The distal condyles of the humerus are preserved as moulds, with a deep groove between them extending half the way up the preserved region. The lateral condyle that articulates with the ulna is wide and rounded, whereas the medial one that articulates with the radius is narrower and longer. This morphology, in anterior view, contrasts with the wide and rounded outlines of both condyles present in Turfanosuchus. However, it is similar to Terrestrisuchus (NHMUK P47/22ii) and Dibothrosuchus (Wu \& Chatterjee, 1993), in which the medial condyle is more pointed and reaches far distally than the lateral condyle (capitellum, Crush, 1984). The distal end of the humerus of Gracilisuchus is 2.5 times wider than the minimum preserved width of the shaft, which contrasts with the much larger proportions of Turfanosuchus (3.75), the smaller proportions of Hesperosuchus agilis Colbert, 1952 (2.2; CM 29894) and Dibothrosuchus (2.08; Wu \& Chatterjee, 1993), but is more similar to Batrachotomus (2.5; SMNS 80276, SMNS 92042), Ticinosuchus (2.7; PIMUZ T2817), Postosuchus (2.4; Weinbaum, 2013) and Terrestrisuchus (2.4; NHMUK $\mathrm{P} 47 / 22$ ii). On the anterior surface near the proximal end, a short and shallow longitudinal groove can be seen that may represent the medial edge of the distal end of the deltopectoral crest (Fig. 16B).

\section{DISCUSSION}

\section{SKELETAL MATURITY OF THE SPECIMENS}

The holotype specimen of G. stipanicicorum (PULR 08) has some characteristics suggesting that it could be the youngest of the six known specimens of this taxon, although the evidence is not conclusive. First, it has the smallest body size; even with an anteriorly incomplete snout the estimated skull length is $73 \mathrm{~mm}$ 
on the basis of the skull of PVL 4597. This estimated skull length is less than the preserved or estimated length of the other specimens (i.e. PVL 4612, MCZ 4117). This proxy is not conclusive by itself and needs caution when interpreting it, because although maturity is correlated with size in living crocodilians, there is variation in size within most ontogenetic stages (Brochu, 1992). The neural arch of the axis of PULR 08 is not fused to the vertebral centrum, showing an open suture, contrasting with the completely closed suture of the axis of MCZ 4118. Additionally, the odontoid process of PULR 08 is missing, suggesting a weak suture or perhaps a lack of fusion with the axis. Because the fusion of the odontoid process and axis occurs late in extant crocodilian development (Rieppel, 1993; Brochu, 1996; Irmis, 2007), the holotype of Gracilisuchus is interpreted as skeletally younger than MCZ 4118. The postaxial cervical vertebrae of PULR 08 lack a closed neurocentral suture, and the dorsal vertebrae that expose this contact (vertebrae 10, 11 and 13) present visible sutures. In contrast, the preserved cervical and dorsal vertebrae of PVL 4597 have closed neurocentral sutures, except for a very faint suture in dorsal 10. Additionlly, MCZ 4118 also has closed sutures in the cervical vertebrae. The condition seen in these specimens is consistent with the pattern of neurocentral suture closure of extant crocodilians, which follow a caudal-to-cranial sequence (Brochu, 1996), consequently suggesting that PULR 08 is skeletally more immature than the referred specimens.

Other differences are also seen between the holotype and the referred material, such as smooth osteoderm ornamentation in the holotype (Buffrénil, 1982; Buffrénil et al., 2015), but this could also be considered as a result of taphonomic processes. These external anatomical features suggest that the holotype specimen might be skeletally more immature than the referred specimens, but the information at hand is not sufficient to infer the minimum ontogenetic age of the hypodigm, or if they have reached somatic maturity. This approach to elucidate the skeletal maturity of the specimens on the basis of the external morphology will hopefully be improved by palaeohistological studies that are currently being conducted.

\section{PHYLOGENETIC ANALYSIS}

To reassess the phylogenetic relationships of $G$. stipanicicorum a phylogenetic analysis was performed based on an extension of the analysis of Lecuona (2013), comprising 81 opertational taxonomic units (OTUs) and 482 characters, which is itself a modified version of the data matrix of Nesbitt (2011), which comprises 77 taxa and 412 characters. In the present contribution we additionally implement the modifications made by Butler et al. (2014) to Nesbitt's (2011) character list.
As a result, the final data matrix has 84 OTUs and 483 chatacters.

\section{Taxon sampling}

The taxonomic list of Nesbitt (2011) comprises a large number of taxa representing several of the different major clades of Archosauriformes (e.g. Erythrosuchidae, Proterosuchidae, Euparkeriidae, Proterochampsidae, Phytosauria, Crocodylomorpha, Pterosauria, Dinosauromorpha). To perform a more exhaustive sampling to test previous phylogenetic hypotheses proposed for Gracilisuchus, some additional species were included by Lecuona (2013), such as the crocodylomorphs Pseudhesperosuchus jachaleri, Junggarsuchus sloani Clark et al., 2004, Trialestes romeri (Reig, 1963) and Hemiprotosuchus leali Bonaparte, 1969. In the present contribution we additionally incorporate the taxa included by Butler et al. (2014), the gracilisuchid Yonghesuchus sangbiensis and the erpetosuchids Erpetosuchus granti and Parringtonia gracilis. From the taxonomic list of Nesbitt (2011), the two terminal taxa Pseudolagosuchus major and Lewisuchus admixtus Romer, $1972 \mathrm{~b}$ were combined into a single terminal (Lewisuchus + Pseudolagosuchus) because they have been proposed as synonyms (Arcucci, 1997, 1998, 2005; Novas et al., 2015) and tested by Nesbitt (2011: 242). The species Prestosuchus chiniquensis was represented by the combination of three specimens (BSP XXV 1-3/5-11/28-41/49, UFRGS 0156-T and UFRGS 0152-T) because no differences were found if treated separately (Nesbitt, 2011: 225).

To score the data matrix, all the specimens deposited in Argentinean collections and many others deposited in the United States and Europe were studied firsthand. A list of the revised specimens and the bibliography used in the present phylogenetic analysis, along with the specimens studied by Nesbitt (2011), are given in Appendix II.

\section{Character sampling}

The character list of the present study (Appendix I) has two sections, the first one corresponding to the original characters proposed by Nesbitt (2011), and the second to additional characters. The characters of the first section were used in the same sense as Nesbitt, unless otherwise stated; two binary characters (17 and 18) were grouped together into a single multistate character, and thus the original character list is reduced by one (411 characters). The second section comprises 71 characters (412-482) added by Lecuona (2013), including characters taken from other previous phylogenetic analyses (Parrish, 1991, 1993; Sereno, 1991; Sereno \& Wild, 1992; Juul, 1994; Clark et al., 2000, 2004; Olsen, Sues \& Norell, 2000) and 15 
new characters $(412,447,448,452,453,456,457,458$, $459,463,465,467,469,476,478)$, which are discussed in Appendix I; finally, character 483 included in the present study was taken from Butler et al. (2014). We have also included here the modifications of Butler et al. (2014) to Nesbitt's (2011) characters 26 and 74. The additive characters are $31,51,58,120,136,138$, $155,167,187,189,222,246,268,270,290,296,313$, $355,370,398,428,430,431$ and 483 . Some characters have been 'reworded' from their original definition. The percentage of missing entries in the data matrix is $44 \%$.

\section{Parsimony analysis}

The data matrix was analysed with the parsimony software TNT (Goloboff, Farris \& Nixon, 2008a, b) v. 1.1 (December 2014). To find the most parsimonious trees (MPTs) we performed a heuristic search, starting with 100 Wagner trees obtained through random addition sequences (RAS) followed by TBR (tree bisection reconnection) branch swapping and holding ten trees per replicate. A second round of TBR branch swapping was done using the trees in RAM, in order to find all MPTs. All characters were treated as equally weighted. A strict consensus (Schuh \& Polhemus, 1980; Sokal \& Rohlf, 1981) of all MPTs was produced. As a measure of group support, three of the most usual parameters were used. The Bremer support (Källersjö et al., 1992; branch support, Bremer, 1994; decay index, Donoghue et al., 1992) indicates how many steps are necessary to lose a particular group in the suboptimal trees. The Bootstrap (Felsenstein, 1985; also Farris et al., 1996) and Jackknife (Tukey, 1958; Lanyon, 1985; Farris et al., 1996) measures indicate the frequency (as a percentage; Absolute Frequency) with which a given group is recovered after performing a series of pseudoreplicates of the original data set by randomly removing and duplicating characters (Bootstrap) or with no duplication (Jackknife) and different algorithms of sampling characters. The Frequency Differences (frequencies GC, Goloboff et al., 2003) goes further and considers not only the recovery frequency but the difference in frequency between a group and the most frequent contradictory group (Goloboff et al., 2003). The resampling measures in this study were performed with a total of 1000 pseudoreplicates and default settings in TNT. To identify the wildcards of the analysis (Nixon \& Wheeler, 1992; Kearney, 2002), we used a TNT tool through the command prunnelsen.

The results of the cladistic analysis produced 32 MPTs of 1674 steps (44 hits out of 100 replicates), with a consistency index (CI; Kluge \& Farris, 1969; Kitching et al., 1998) of 0.346 and a retention index (RI; Farris, 1989) of 0.734 (Fig. 17).

\section{General topology and support values}

The strict consensus of the 32 MPTs is well resolved, being consistent with the results obtained by Nesbitt (2011) for most of the clades, but resolving some previous polytomies in comparison with the original analysis. The relationships among basal non-archosaurian taxa are congruent with Nesbitt's results, including the sister group relationship between Phytosauria and Archosauria, retrieved with high support values (Figs 17, S6, Table S10).

Archosauria and its two major lineages, Pseudosuchia and Ornithodira, have Bremer support values of 3 but the resampling values are somewhat low for Archosauria and Pseudosuchia (<50\%), whereas Ornithodira is better supported. The Archosauria Bootstrap support is $36 \% / 27 \%$ and Jackknife value is 45\%/38\% for Absolute Frequency and Frequency GC, respectively. These values indicate that Archosauria is recovered in 36 and $45 \%$ of the 1000 pseudoreplicates (Bootstrap and Jackknife, respectively), and the group that most frequently contradicts it is recovered 9 and $7 \%$ of the times (for Bootstrap and Jackknife, respectively). The Pseudosuchia node has Bootstrap support values of $18 \% / 13 \%$ and Jackknife values of 25\%/21\% (Absolute Frequency/Frequency GC; Figs 17, S6, Table S10).

Ornithosuchidae, constituted by Riojasuchus tenuisceps and Ornithosuchus longidens, has a Bremer support of 4 and high resampling support values (both Bootstrap of $97 \%$ and both Jackknife of $98 \%$, Fig. S6). Ornithosuchidae is the sister group of Suchia, and the basal node of the latter is fully resolved in our results, contrasting with the original analysis (Nesbitt, 2011) that showed a polytomy formed by Gracilisuchus, Turfanosuchus, Revueltosaurus callenderi + Aetosauria, and Ticinosuchus ferox + Paracrocodylomorpha. The complete dichotomic resolution of this node could be due in part to the addition of several taxa that are depicted in this area of the cladogram, and also probably because of the rescoring of several characters and addition of others. Similar results with a lower number of taxa were retrieved in two recent analyses that included some of the new anatomical information described here (i.e. Lecuona, 2013; Butler et al., 2014).

Support for the node of Suchia is extremely low, with a minimal Bremer support and resampling values as low as 2\%/-8\% for Bootstrap Absolute Frequency and Frequency GC and 4\%/-3\% for Jackknife Absolute Frequency and Frequency GC (Figs 17, S6, Table S10). In Butler et al.'s (2014) analysis, Suchia is better supported by the Bremer support (value of 3 ), but its Bootstrap values are 53\%/29\%. In our analysis Suchia is contradicted fewer times (10\% of times for Bootstrap) than in Butler et al.'s (2014) analysis (24\% 
of times). Suchia diverges into two subclades that also have low support (Bremer value of 1 and low resampling values). One of these subclades has a Bootstrap of $5 \% /-4 \%$ and Jackknife of $8 \% / 0 \%$ (Absolute Frequency/ Frequency GC for each measure), and is formed by two subclades, Erpetosuchidae (Parringtonia gracilis + Erpetosuchus granti) and Revueltosaurus + Aetosauria, which are in turn relatively well supported (Figs 17, S6). Erpetosuchidae has a Bremer value of 4 , Bootstrap of $73 \% / 72 \%$ and Jackknife of $81 \% / 80 \%$ (Absolute Frequency/Frequency GC); these values reflect the improvement in our understanding of the position of this clade, which was uncertain in previous studies (Nesbitt \& Butler, 2012; Butler et al., 2014). The clade of Revueltosaurus + Aetosauria has a Bremer support of 5 and Bootstrap and Jackknife of $79 \% / 79 \%$ and $89 \% / 89 \%$. The clade is less well supported by Bremer value than in the analyses of Nesbitt (2011; Bremer of 9) and Butler et al. (2014; Bremer of 10). Conversely, Bootstrap support for this clade is slightly higher in our analysis, given the difference between the Absolute Frequency and Frequency GC is $0 \%$, and thus no contradictory clade is present; by contrast, in Butler et al.'s (2014) analysis this difference is $1 \%$, and thus there is a clade recovered $1 \%$ of times that contradicts Revueltosaurus + Aetosauria.

The second subclade of Suchia comprises Gracilisuchidae + (Ticinosuchus + Paracrocodylomorpha) and also has low support, a Bremer value of 1 and Bootstrap and Jackknife of 3\%/-2\% and 6\%/0\%, respectively. The relationship of these taxa is consistent with the results recently obtained by Butler et al. (2014) when erpetosuchids were excluded (because in the analysis of those authors the inclusion of the erpetosuchids created a large polytomy around the base of Archosauria). This clade is less well supported by the Bremer value in the present study than in the study by Butler et al. (2014) (1 vs. 3), but the opposite is true for the Bootstrap values, which are 46 and $37 \%$ in the latter analysis (Table S10). These values indicate that in our analysis this clade is contradicted fewer times by the most contradictory clade than in the previous analysis (5\% vs. 9\%). The clade Gracilisuchidae has a relatively high Bremer support value of 4 , but low resampling measures (Bootstrap of $27 \% / 26 \%$ and Jackknife of $42 \% / 41 \%$ ). The Bremer value is the same as Butler et al. (2014) but the Bootstrap values are lower (66\%/55\% in the latter study). However, in our analysis there is a smaller difference between the Absolute Frequency and Frequency GC for both resampling methods, meaning that the most frequent clade that contradicts Gracilisuchidae is recovered with very low frequencies (1\% of times for Bootstrap) compared to the analysis of Butler et al. (2014) (11\% of times; Figs 17, S6, Table S10; Butler et al., 2014: online

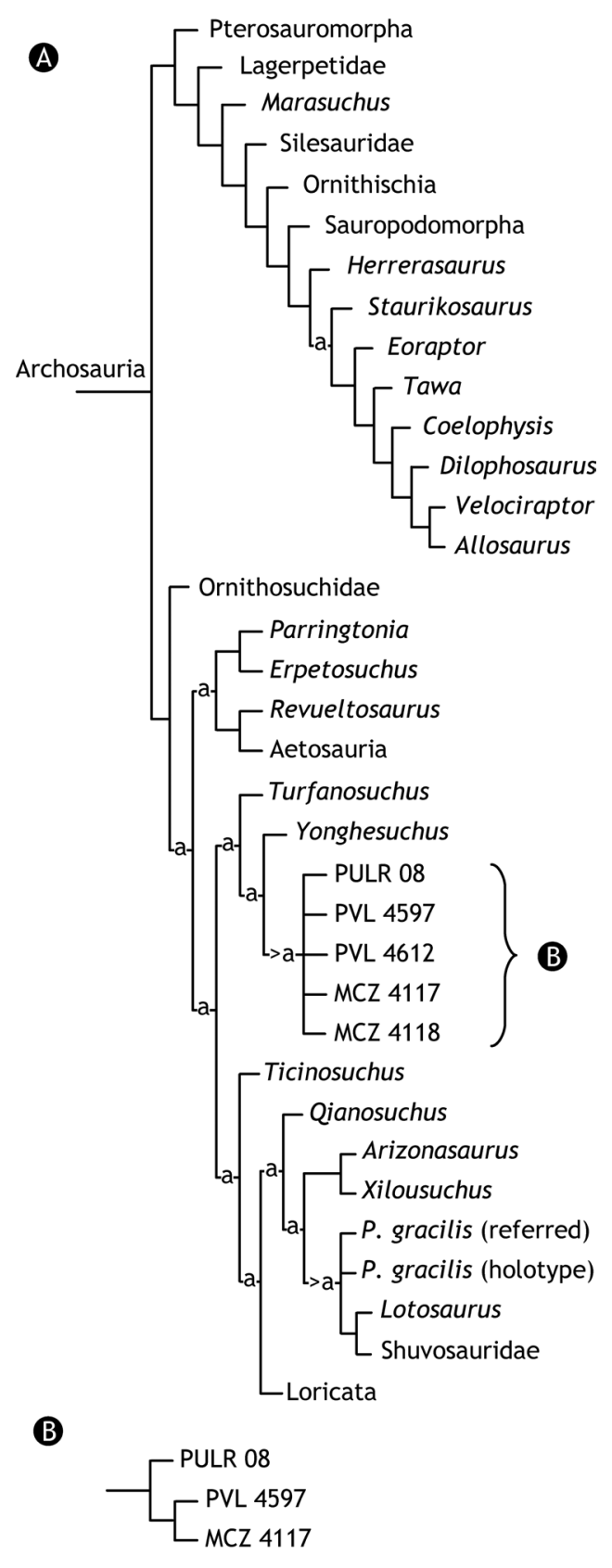

Figure 19. Phylogenetic relationships obtained including the six specimens of $G$. stipanicicorum. Reduced strict consensus pruning MCZ 4116, showing the different positions in the tree marked with an 'a' (A); relationships among specimens of Gracilisuchus pruning PVL 4612 and MCZ 4118 (B).

supplementary material). Within Gracilisuchidae, Turfanosuchus dabanensis is the basalmost taxon and sister taxon to the clade of Yonghesuchus sangbiensis + Gracilisuchus stipanicicorum (which has a Bremer of 2 and Bootstrap and Jackknife of 35\%/27\% and $40 \% / 32 \%$, respectively). The Bremer value is 
somewhat better than the minimal value obtained by Butler et al. (2014), as well as the Bootstrap values (43\%/19\% for the latter study). In our analysis, the clade is contradicted fewer times by the most frequent contradictory clade ( $8 \%$ of times for Bootstrap) than in Butler et al. (2014; $24 \%$ of times) (Table S10). An additional improvement with respect to the latter analysis is the recovery of a dichotomic Gracilisuchidae when Erpetosuchidae is included, in contrast to the polytomic Gracilisuchidae recovered when Erpetosuchidae was included in the analysis (Butler et al., 2014: supplementary material).

The clade composed of Ticinosuchus ferox + Paracrocodylomorpha has low support values (Bremer of 2, Bootstrap of 7\%/2\% and Jackknife of 13\%/9\%) and the topology obtained here is consistent with previous phylogenetic analyses (Nesbitt, 2011; Butler et al., 2014). The major difference with the previous analyses occurs in the position retrieved for different taxa within Crocodylomorpha (Fig. 18; Table S10). The first difference is seen in the third node from the base, where a trichotomy is formed by Trialestes romeri, Pseudhesperosuchus jachaleri and more derived crocodylomorphs (Bremer value of 2 and low resampling measurements). Sphenosuchus acutus is the next most derived taxon, followed by the monophyletic group of Terrestrisuchus gracilis and Dibothrosuchus elaphros, in contrast to the previous analyses that found them in a polytomy. The next most derived group is constituted by the trichotomy of Litargosuchus leptorhynchus, Kayentasuchus walkeri and Crocodyliformes, which in the present analysis is less resolved than in previous ones where Litargosuchus was basal to the two other taxa (Nesbitt, 2011). Crocodyliformes is formed by the trichotomy of Hemiprotosuchus leali, Alligator mississippiensis + Junggarsuchus sloani and Orthosuchus stormbergi + Protosuchus spp., and has low support values (Figs 18, S6, Table S10). This result contrasts with the previous one (Nesbitt, 2011), where a trichotomy was formed by Alligator, Orthosuchus and Protosuchus spp., because of two taxa added to the matrix here.

\section{Analysis of the most parsimonious phylogenetic hypotheses}

In this section we discuss the position of Gracilisuchus within Suchia and Pseudosuchia, including the synapomorphies that support that grouping, the characters that keep it outside the more deeply nested suchian clades, and the synapomorphies of more basal and derived nodes.

Pseudosuchia node: This clade has relatively low support values (see above; Figs 17, S6) but is diagnosed by seven unambiguous synapomorphies common to all the MPTs. Five of the synapomorphies are from the original list of characters (Nesbitt, 2011), which are character-states 99.1, 237.1, 329.1, 336.1 and 371.1; and from the new character list are character-states 457.1 and 466.1. In particular, character-state 371.1 is the presence of a smooth crest separating the calcaneal articular facets for fibula and astragalus, although this is reverted in the gracilisuchids Gracilisuchus and Turfanosuchus (370.0).

One of the new pseudosuchian synapomorphies is the presence of a ventral keel on anterior dorsal vertebrae (457.1), present in many pseudosuchian taxa such as Riojasuchus, Erpetosuchidae, Arizonasaurus babbitti, Postosuchus kirkpatricki, P. alisonae and Hesperosuchus agilis (referred specimens), whereas in Ornithodira and non-archosaurian archosauriforms, such structures are absent (457.0). Nevertheless, within Pseudosuchia, there are some reversals to the absence of the keels, such as in Gracilisuchus, Effigia okeeffeae, Dromicosuchus grallator and Dibothrosuchus elaphros. The other new pseudosuchian synapomorphy is a pubis that shortly participates in the formation of the acetabulum (466.1). Gracilisuchus and Batrachotomus kupferzellensis are autapomorphic for this characterstate, the first due to the lack of a pubic participation (466.2) and the second due to its wide contribution to the acetabulum (466.0). Non-archosaurian archosauriforms and basal ornithodirans (e.g. Marasuchus lilloensis) have a wide participation of the pubis in the acetabulum (466.0).

Suchia node: In the present analysis Suchia is supported by five unambiguous synapomorphies common to all the MPTs but has low support values. All five synapomorphies are from the first section of the character list (i.e. Nesbitt, 2011 characters), which are $74.1,113.2,233.0,375.2$ and 377.1. The first synapomorphy, presence of a longitudinal ridge on the lateral surface of the jugal body (74.1), is present in several Suchia including the gracilisuchids Gracilisuchus and Turfanosuchus but there is a reversal in Yonghesuchus that lacks this ridge (74.0).

Erpetosuchidae + (Revueltosaurus + Aetosauria) node: This clade has very low support values (see above) and is supported by two unambiguous synapomorphies common to all MPTs. The first is from the original character list (405.1) and the second is from the characters added in this analysis (418.1). The latter optimizes as a synapomorphy but has to be taken with caution because only two taxa were able to be scored out of six taxa that compose this clade in the analysis. Erpetosuchus and Revueltosaurus have a postorbital located medial to the jugal in the 
postorbital bar (418.1). Ornithosuchus has a postorbital located anterior to the jugal in the postorbital bar (418.0), as well as Gracilisuchus and derived Suchia. The Gracilisuchidae node is optimized with state 0, but in Turfanosuchus the condition is unknown and Yonghesuchus has the third character state because the postorbital is lateral to the jugal (418.2). The other synapomorphy refers to the presence of two pairs of paramedian rows of osteoderms (four osteoderms per segment) (405.1). This character-state is present in Aetosauria and Erpetosuchus but is undetermined in Parringtonia and Revueltosaurus. The remaining taxa of the matrix that can be scored present a single row of paramedian osteoderms (405.0), with the exception of living crocodilians. This character is not very homoplastic and it will be interesting to know if Parringtonia and Revueltosaurus present the same synapomorphic state.

Gracilisuchidae + (Ticinosuchus ferox + Paracrocodylomorpha) node: This group has low general support (see above), being supported by five unambiguous synapomorphies common to all MPTs. The first four $(351.1,402.1,409.1,410.0)$ are from the first section of the character list and the fifth (448.0) derives from the second section. One synapomorphy is the presence of a foramen on the medial side of the distal tarsal 4 (351.1). This foramen is present in Gracilisuchus (Lecuona, 2007; Lecuona \& Desojo, 2011), so the scoring for this entry was changed from missing data in the original analysis (Nesbitt, 2011). Another synapomorphic character is the presence of staggered dorsal paramedian osteoderms, meaning that the osteoderms of each pair are slightly anteroposteriorly offset with respect to each other (410.0). This is the condition present in Gracilisuchus, thus changing the scoring in the present study. The synapomorphy of the new character added in this study is the location of the posterior edge of the axial neural spine, anteriorly or at the same level as the posterior limit of the postzygapophysis (448.0). This condition is present in Gracilisuchus, Arizonasaurus and Saurosuchus, whereas in more basal members of Pseudosuchia (e.g. Riojasuchus, Erpetosuchus) the posterior limit is posterior to the posterior limit of the postzygapophysis (448.1); nevertheless there are still many missing data in this character.

Gracilisuchidae node: Seven synapomorphies common to all MPTs diagnose this clade, six from the first character list $(4.3,36.1,42.1,66.1,371.0,403.1)$ and the seventh from the second part of the list (483.2).

From the first section, the presence of a posterodorsal process of the premaxilla that fits into a slot of the nasal (character 4.3) is also convergently present in
Revueltosaurus. A second character, the participation of the nasal in the dorsal border of the antorbital fossa (36.1), is present in all three gracilisuchids but is also convergently acquired in Aetosaurus, Batrachotomus and other more derived taxa. Conversely, the lack of participation of the nasal in the antorbital fossa (36.0) is present in Ornithosuchidae, Erpetosuchus, Revueltosaurus, and in more derived Suchia as Qianosuchus, Prestosuchus chiniquensis and several members of Crocodylomorpha (e.g. Hesperosuchus, Dromicosuchus). The third synapomorphy is the presence of an anteriorly tapering frontal along the midline (42.1), which is present in Gracilisuchus and Turfanosuchus, but unknown in Yonghesuchus. This character-state is also convergently present in several taxa such as Shuvosauridae, Batrachotomus, Postosuchus and most crocodylomorphs. Conversely, a frontal with a wide anterior portion (42.0) is present in Ornithosuchidae, Aetosauria and non-archosaurian archosauriforms. In the three gracilisuchid taxa the postorbital bar is formed mostly by the postorbital bone (66.1), contrasting with more derived taxa (Qianosuchus, Arizonasaurus, Crocodylomorpha) and the basalmost pseudosuchians (Ornithosuchidae and Erpetosuchidae) that have the postorbital bar composed by both jugal and postorbital in nearly equal proportions (66.0). The fifth synapomorphy of the group is the presence of continuous articular facets for the fibula and astragalus in the calcaneum (371.0), present in Gracilisuchus (modified from the original scoring of Nesbitt, 2011) and Turfanosuchus, but unknown in Yonghesuchus. It will be important to know this feature in Yonghesuchus in order to determine if it is a real synapomorphy of Gracilisuchidae. In contrast, other pseudosuchians have the facets for the astragalus and fibula in the calcaneum separated (371.1), such as Revueltosaurus, Aetosauria, Ticinosuchus, Poposauroidea, basal Loricata and Crocodylomorpha (e.g. Hesperosuchus, Terrestrisuchus). The condition found in Gracilisuchidae is actually a reversal to the ancestral state present in non-archosaurian archosauriforms (e.g. Erythrosuchus africanus, Vancleavea campi, Tropidosuchus, Phytosauria). Another synapomorphy is the presence of presacral paramedian osteoderms with a distinct longitudinal bend (403.1), present in Gracilisuchus and Turfanosuchus (unknown in Yonghesuchus). This character state is also present convergently in Erpetosuchidae, the basal loricatan Batrachotomus, and Fasolasuchus, Rauisuchidae and some Crocodylomorpha (e.g. Dromicosuchus, Dibothrosuchus). Conversely, basal suchians, such as Ornithosuchidae, Revueltosaurus, Aetosauria, Ticinosuchus, Prestosuchus, Saurosuchus and some Crocodylomorpha, such as Hemiprotosuchus, have flat or weakly arched paramedian presacral osteoderms (403.0). 
Finally, the last synapomorphy is the presence of a posterodorsal process in the posterior process of the maxilla, although the degree of development of this process varies within the group. Gracilisuchus has a weakly developed posterodorsal process of the maxillary posterior process, where the dorsal extension of the posterodorsal process is less than the height of the horizontal process of the maxilla immediately anterior to the posterodorsal process (483.1). Conversely, Turfanosuchus and Yonghesuchus have a well-developed posterodorsal process of the maxillary posterior process extending dorsally over the dorsal margin of the horizontal process by almost the same height as the horizontal process of the maxilla immediately anterior to the posterodorsal process (483.2). In most other taxa, the posterodorsal process of the posterior process of the maxilla is absent (483.0), such as non-archosaurian archosauriforms, ornithosuchids, Erpetosuchus, Ticinosuchus and loricatans. Exceptions to this distribution are found in some pseudosuchians that have character state 1 (i.e. Aetosauria, Qianosuchus, Dibothrosuchus).

Gracilisuchus stipanicicorum + Y. sangbiensis node: This group was also obtained by Butler et al. (2014), having here slightly higher support values but that are nonetheless low (see above, Figs 17, S6, Table $\mathrm{S} 10)$. Four unambiguous synapomorphies diagnose this clade, three of which are from the first section of the character list $(65.1,71.1,102.1)$ and one from the new characters added in this study (440.2). The first synapomorphy that joins together Gracilisuchus and Yonghesuchus is the contact between postorbital and squamosal continuing ventrally for most of the ventral length of the squamosal (65.1), whereas in Turfanosuchus the contact between the elements is restricted to their dorsal region (65.0). The derived character state (65.1) is also present in other pseudosuchians, such as Revueltosaurus, Aetosaurus, Postosuchus and Crocodylomorpha (e.g. Dromicosuchus, Pseudhesperosuchus, Sphenosuchus). In contrast, the plesiomorphic character state (65.0) is present in Erpetosuchus, Ornithosuchidae and non-archosaurian archosauriforms. The posterior end of the jugal in Gracilisuchus and Yonghesuchus is located posteriorly to the lower temporal fenestra (71.1), whereas in Turfanosuchus is located anteriorly (71.0). The latter character state is also seen in Revueltosaurus, Aetosauria, Ornithosuchidae, Poposauroidea and some basal Loricata, but not in Postosuchus or Crocodylomorpha (e.g. Hesperosuchus, Sphenosuchus, Terrestrisuchus), in which the jugal finishes posterior to the lower temporal fenestra. Another synapomorphy is the presence of a very elongated (at least 1.5 times longer than wide) parabasisphenoid between the basal tubera and basipterygoid processes (102.1), contrasting with the parabasisphenoid of Turfanosuchus that is wider than long (102.0). Other taxa also have the plesiomorphic character state where the parabasisphenoid is wider than or as wide as long between the basal tubera and basipterygoid processes, such as Riojasuchus, Aetosauria, Qianosuchus, Prestosuchus, Saurosuchus and non-archosaurian archosauriforms. A long parabasisphenoid is convergently present in some more derived taxa as P. kirkpatricki and Dibothrosuchus. The last synapomorphy of Gracilisuchus + Yonghesuchus is the lack of participation of the postorbital in the infratemporal fenestra (440.2), contrasting with the condition in Turfanosuchus, where the postorbital has a large participation on the anterodorsal part of the infratemporal fenestra (440.0). The latter condition is also seen in Ornithosuchidae, Stagonolepis, Qianosuchus, Batrachotomus and some basal Crocodylomorpha (e.g. Litargosuchus, Hemiprotosuchus). The lack of participation in the infratemporal fenestra is also present in other taxa, such as Revueltosaurus, Postosuchus kirkpatricki and Hesperosuchus agilis (referred specimens). Conversely, a nearly excluded postorbital (440.1) is present in Erpetosuchus and protosuchids.

\section{Testing alternative positions of $\mathrm{G}$. stipanicicorum}

The different phylogenetic hypotheses previously proposed for Gracilisuchus are tested within the context of the present dataset after conducting heuristic tree searches constraining the position of Gracilisuchus. The results of the six previously proposed positions of this taxon are discussed in this section.

Gracilisuchus within Ornithosuchidae: The first hypothesisforGracilisuchus relationships was proposed by Romer (1972a), suggesting that it was closely related to the Scottish ornithosuchid Ornithosuchus (Walker, 1964), and subsequently followed by others (e.g. Bonaparte, 1972, 1975b). Forcing the monophyly of Gracilisuchus + Ornithosuchidae results in 384 trees of 1690 steps (16 extra steps), where Gracilisuchus is found as the sister taxon to Riojasuchus + Ornithosuchus. The strict consensus shows a large polytomy in the node Pseudosuchia, formed by this new group along with Erpetosuchidae, Yonghesuchus + Turfanosuchus, Ticinosuchus, Revueltosaurus + Aetosauria and Paracrocodylomorpha. The clade that clusters Gracilisuchus as a member of Ornithosuchidae lacks unambiguous synapomorphies, meaning that 
this hypothesis is not plausible with the data of the present analysis.

Gracilisuchus as the basalmost suchian: Benton \& Clark (1988) found Gracilisuchus in the dichotomy of their node Suchia, where Phytosauridae was the sister group of Suchia, and both forming Crocodylotarsi. Constraining the analysis to locate Gracilisuchus in the basalmost position of Suchia resulted in 64 trees of 1687 steps, the strict consensus of which shows a polytomy at the base of Suchia formed by Ticinosuchus, Erpetosuchidae, Yonghesuchus + Turfanosuchus, Revueltosaurus + Aetosauria, Gracilisuchus and Paracrocodylomorpha. Although the monophyly of the following node as being more derived than Gracilisuchus was also forced in order to keep the position of Gracilisuchus as sister taxon to all other Suchia, the result was a polytomy in the consensus because no synapomorphy defines the node of the remaining Suchia; it is a zero length branch. This hypothesis requires 13 extra steps compared with the unconstrained analysis and no unambiguous synapomorphies support the group, indicating that this hypothesis is clearly rejected by the data of this analysis.

Gracilisuchus + Paracrocodylomorpha monophyly: Parrish (1993) found Gracilisuchus as the sister taxon of Paracrocodylomorpha (formed by Poposauroidea and Crocodylomorpha), and these three taxa formed the sister clade of Rauisuchidae (sensu Parrish, 1993). To test this hypothesis, we constrained both the monophyly of Poposauroidea + Crocodylomorpha and the position of Gracilisuchus as their sister taxon. The analysis resulted in 78 trees of 1714 steps (40 extra steps), and many polytomies in the consensus. Gracilisuchus is shown as collapsed with Yonghesuchus, Turfanosuchus and Crocodylomorpha + Poposauroidea, and the whole group collapsed in a tetrachotomy at the base of Suchia. A second test was performed constraining only the monophyly of Gracilisuchus and Paracrocodylomorpha, which resulted in 32 trees of 1686 steps (12 extra steps). Gracilisuchus was found as the sister taxon to Loricata with five supporting synapomorphies. None of these results are plausible with the data of this analysis, being considerably longer than the unconstrained MPTs.

Gracilisuchus as the sister taxon of Postosuchus: Juul (1994) recovered Gracilisuchus and Postosuchus grouped together and depicted them as sister taxa of Crocodylomorpha (forming Paracrocodylomorpha). Paracrocodylomorpha in turn was found as the sister taxon to Ornithosuchidae, forming the clade Dromaeosuchia (Juul, 1994). In Juul's analysis the OTUs were mostly higher-level taxa rather than species or genera, so to make this constraint we have forced the monophyly of Gracilisuchus with Rauisuchidae (the clade containing Postosuchus) rather than with Postosuchus itself. This is because of poor sampling of species-level taxa in Juul's study that lacked other 'rauisuchians' closer to Postosuchus than to Gracilisuchus. This resulted in 24 trees of 1704 steps, considerably longer than in the first constraint. Gracilisuchus as sister taxon of Rauisuchidae is supported by three synapomorphies, but the 30 extra steps required by this topology makes this hypothesis highly suboptimal with this data matrix.

Gracilisuchus + Phytosauridae monophyly: Li et al. (2006) obtained Gracilisuchus as the sister taxon of Phytosauridae, a clade forming part of a polytomy at the base of Crurotarsi. Forcing the monophyly of Gracilisuchus and Phytosauridae results in 32 trees of 1693 steps, this group being supported by two synapomorphies. The need for 19 extra steps to place Gracilisuchus in this position demonstrates that this hypothesis is rejected by the data at hand.

Gracilisuchus + Crocodylomorpha monophyly: The hypothesis of Gracilisuchus being closely related to Crocodylomorpha had been accepted in recent analyses (e.g. Brusatte et al., 2010). To test this it was necessary to force the monophyly not only of Gracilisuchus + Crocodylomorpha but also of Crocodylomorpha itself, otherwise Gracilisuchus was nested within Crocodylomorpha (one node above from its base and in a polytomy with other basal Crocodylomorpha). This constraint results in 492 trees of 1700 steps. The need for 26 extra steps to locate Gracilisuchus in that position makes this hypothesis unlikely; nevertheless, there are 16 unambiguous synapomorphies common to all MPTs that diagnose this clade. This number of synapomorphies suggests that there are many derived similarities between Gracilisuchus and Crocodylomorpha, but in the context of this analysis, they are most parsimoniously interpreted as convergences. Additionally, under this topology the optimization of the characters reveals 39 autapomorphies for Gracilisuchus, many of which represent plesiomorphies of Suchia and Pseudosuchia in the constrained and unconstrained analyses. Consequently, this result shows this interpretation as also unlikely with this analysis.

\section{Exploring the taxonomic identity of the referred specimens of $\mathrm{G}$. stipanicicorum}

To evaluate the identity of G. stipanicicorum as a single taxonomic unit, all six specimens known for this species (i.e. PULR 08, PVL 4597, PVL 4612, MCZ 
4117, MCZ 4116, MCZ 4118) were incorporated in the data matrix as separate OTUs. The results of a tree search of this data matrix gave 720 MPTs of 1680 steps (six steps longer than the original analysis). The strict consensus displays a polytomy of 27 branches in the node Archosauria. This is largely caused by the unstable behaviour of MCZ 4116, which takes 12 different positions within Pseudosuchia and Ornithodira (a, Fig. 19A). Pruning this OTU ('prunnelsen' tool in TNT) resolves 20 nodes in the strict consensus tree. This reduced strict consensus tree shows the other five specimens of Gracilisuchus clustered together in a polytomy and placed within Gracilisuchidae (in the same position as in the original analysis; Fig. 19A). The large amount of alternative positions that MCZ 4116 takes is not due to the presence of conflictive data, but due to the lack of relevant scorings of this specimen (94.4\% of missing data). The second most unstable taxon is Hesperosuchus agilis (AMNH FR 6758) followed by PVL 4612 and MCZ 4118 Gracilisuchus specimens. The reduced strict consensus obtained by pruning these specimens shows PULR 08 as sister group to MCZ 4117 + PVL 4597 (Fig. 19B). On the basis of this exploratory analysis, the taxonomic assignment of the referred specimens to G. stipanicicorum is highly supported. MCZ 4116 is phylogenetically uninformative, but it is assigned to this species due to the presence of a unique combination of character-states shared with other Gracilisuchus specimens (e.g. postfrontal present, large antorbital fenestra, proximally located ischiadic symphysis and flat ischiadic apron).

\section{Autapomorphies of G. stipanicicorum}

Three autapomorphies are recovered from the optimization of all MPTs. The first is the presence of four premaxillary teeth (6.1), contrasting with Turfanosuchus and Yonghesuchus that possess five (6.2). The condition of Gracilisuchus is not unique and is convergent with that of basal loricatans (Prestosuchus, Saurosuchus, Fasolasuchus, Batrachotomus), Rauisuchidae and Crocodylomorpha (Kayentasuchus, Litargosuchus, Protosuchidae). A second autapomorphy is the presence of a lacrimal as high as the orbit and contacting the jugal at the level of the ventral margin of the orbit (38.1), contrasting with the low lacrimal present in Turfanosuchus and Yonghesuchus that is significantly lower than the height of the orbit (38.0). Gracilisuchus shares this character state with Tropidosuchus, all Crocodylomorpha that were possible to score (Hesperosuchus, Dromicosuchus, Sphenosuchus, Junggarsuchus) as well as in early Theropoda. The last autapomorphy of Gracilisuchus is the presence of a jugal posterior process lying ventral to the anterior process of the quadratojugal (70.1).
In Turfanosuchus and Yonghesuchus the process lies dorsal to the anterior process of the quadratojugal (70.0). This autapomorphy is shared convergently with Erpetosuchus, Postosuchus kirkpatricki, Polonosuchus and Crocodylomorpha.

The three character-states obtained as autapomorphies of Gracilisuchus in this phylogenetic analysis are also present in other taxa including Crocodylomorpha. These characters are interpreted as convergences based on the present phylogenetic results, which depict Gracilisuchus as a basal Suchia. The presence of these characters in both Gracilisuchus and Crocodylomorpha, along with the large number of synapomorphies recovered when their monophyly is forced (see above), probably contributed to previous authors interpreting them as derived similarities and postulating the affinities of Gracilisuchus to Crocodylomorpha (e.g. Clark et al., 2000, 2004; Sues et al., 2003; Brusatte et al., 2010; Pol et al., 2012). However, this hypothesis lacks support with the data of the present analysis.

\section{CONCLUSIONS}

Our study of the postcranial axial skeleton, forelimb and osteoderms of Gracilisuchus stipanicicorum based on the holotype (PULR 08) and referred specimens (PVL 4597, MCZ 4116, MCZ 4117, MCZ 4118) resulted in the discovery of autapomorphies that improve the diagnosis of this species. The taxonomic identity of the referred material is corroborated here on the basis of a unique combination of characters and tested through a specimen-based exploratory phylogenetic analysis.

The holotype specimen (PULR 08) probably represents an immature specimen, as suggested by its smaller size relative to the referred specimens, as well as several skeletal features characteristic of immature specimens of extant crocodilian species. The inclusion of the holotype specimen in the present phylogenetic analysis and conducting the analysis only with this specimen does change the results, placing it as the sister taxon to Yonghesuchus as a basal crocodylomorph. However, all synapomorphies supporting this position have the same character-states in the holotype and the referred specimens, when scored. Consequently, the difference in topology is not affected by the immaturity of PULR 08 but by its incomplete preservation; the possition recovered in the complete analysis is largely influenced by the scored characters of the referred specimens. As a result, the potentially ontogenetically related character-states of PULR 08 may have not been directly affecting our understanding of the species, probably because this is based on a larger number of characters, including those unrelated to ontogeny, or because these characters may be affecting earlier 
or older developmental stages, and mostly because all the hypodigm is contributing in the same sense to our knowledge of Gracilisuchus.

The phylogenetic relationships tested through the expansion of previous contributions (Nesbitt, 2011; Butler et al., 2014), with the incorporation of new characters and taxa, found Gracilisuchus within the recently erected Gracilisuchidae (Butler et al., 2014) lying at the base of Suchia, supporting the results of recent studies. Nonetheless, several improvements were obtained over the previous analyses. Firstly, the relationships of basal nodes in Suchia are fully resolved in the present analysis, compared with the polytomy present in the previous analysis (Nesbitt, 2011). Secondly, some of the new taxa included in the present study are recovered as basal suchians, and thus the resolution of the previous polytomy might be due in part to the incorportation of these taxa in the data matrix, and also probably to the rescoring of characters of the original data matrix (Lecuona, 2013; Butler et al., 2014). Finally, Erpetosuchidae is recovered as sister group to Revueltosaurus + Aetosauria.

The clade Erpetosuchidae was recently revised as a result of the reappraisal of the erpetosuchid Parringtonia gracilis (Nesbitt \& Butler, 2012), which belongs to this clade together with Erpetosuchus granti. Erpetosuchidae was a wildcard in this study and in that of Butler et al. (2014), but being nested with Revueltosaurus + Aetosauria in some of their MPTs. The present analysis found Erpetosuchidae as the sister taxon to Revueltosaurus + Aetosauria in all MPTs, supporting some of the topologies of the previous analyses. This result contrasts with earlier hypotheses that interpreted Erpetosuchus as the closest relative of Crocodylomorpha (e.g. Benton \& Walker, 2002; Brusatte et al., 2010). The present analysis does not support a close relationship between Erpetosuchidae and Crocodylomorpha, and thus a new interpretation is required for the timing of the origin of Crocodylomorpha, as well as for Revueltosaurus + Aetosauria. The sister-group relationship proposed here implies that the ghost lineage of Revueltosaurus + Aetosauria is restricted to the latest Anisian (fossil record of Parringtonia) to the late Carnian (fossil record of Aetosauroides, Desojo \& Ezcurra, 2011).

The constraints of monophyly performed to test the alternative hypotheses of relationships of Gracilisuchus strongly reject its previously proposed affinities with Phytosauridae, Ornithosuchidae, Paracrocodylomorpha, Postosuchus (and Rauisuchidae) and Crocodylomorpha, and as the basalmost member of Suchia. These alternative hypotheses are not supported by the data of the current analysis, because they require between 13 and 40 extra steps compared with the unconstrained parsimony analysis. Thus, the affinities of Gracilisuchus as a member of Gracilisuchidae and positioned two nodes above the Suchia node, and as a sister taxon to Ticinosuchus + Paracrocodylomorpha, are supported by the data of the present analysis.

\section{ACKNOWLEDGEMENTS}

We would like to thank E. Vaccari (UNLaR) and the late J. Powell (PVL) for the loan of fossil material of Gracilisuchus and the visit to the collections for comparisons with other taxa. Visits to other collections was possible thanks to O. Alcober and R. Martinez (PVSJ), K. Padian and P. Holroyd (UCMP), M. Norell and C. Mehling (AMNH), V. Schneider (NCSM), A. Henrici and C. Beard (CM), M. Brett-Surman and C. Ito (USNM), J. Cundiff, M. Lyons and F. A. Jenkins Jr (MCZ), D. Binkman, C. Norris and J. Gauthier (YPM), S. Bandyopadhyay (ISI), D. Vasilyan and H. Stöhr (GPIT), R. Schoch (SMNS) and H. Hagdorn (MHI). The comparison with living crocodilian specimens was possible thanks to E. Ruigómez (MPEF-AC), J. Faivovich (MACN-He) and A. Scanferla. We appreciate the kind contribution of M. Ezcurra of many specimen photographs (IVPP, PIMUZ), and valuable discussions and suggestions on the manuscript. We are also thankful to J. Gauthier for providing us with the photographic library 'Euparkeria: An Image Library'. Reconstruction of Gracilisuchus was performed by J. González, and preparation of the fossil material was done by P. Puerta, L. Canessa and L. Reiner (MEF). We are grateful to the anonymous referees, whose suggestions greatly improved the manuscript. Access to the free version of TNT 1.1 was possible due to the Willi Henning Society. Financial support to A.L. for collection visits was provided by the Sylvester-Bradley Award (Palaeontological Association), the Theodore Roosevelt Memorial Fund (AMNH), the Welles Fund (UCMP) and the Deutscher Akademischer Austauschdienst (DAAD). Financial support was provided to A.L. by the Sylvester-Bradley Award (2010) of the Palaeontological Association, the Theodore Roosevelt Memorial Fund (2010) of the American Museum of Natural History (AMNH), the Welles Fund (2010) of the University of California Museum of Paleontology (UCMP), and the Research Grants - Short-Term Grants, 2015 (57130097) of the Deutscher Akademischer Austauschdienst (DAAD) to visit several palaeontological collections abroad.

\section{REFERENCES}

Allen RC. 2010. The anatomy and systematics of Terrestrisuchus gracilis (Archosauria, Crocodylomorpha). PhD Thesis, Department of Biological Sciences Northern Illinois University. 
Arcucci AB. 1997. Dinosauromorpha. In: Currie PJ, ed. Encyclopedia of dinosaurs. San Diego: Academic Press, 179-183.

Arcucci AB. 1998. New information about dinosaur precursors from the Triassic Los Chañares fauna, La Rioja, Argentina. Journal of African Earth Sciences 27: 9-10.

Arcucci AB. 2005. Una reevalución de los dinosauriomorfos basales y el origen de Dinosauria. In: Kellner AWA, Henriques DDR, Rodriques T, eds. Boletim de Resumos do II Congresso Latino-americano de Paleontologia de Vertebrados. Río de Janeiro: Museu Nacional, Rio de Janeiro, Serie Livros 12, 33.

Baczko MB von, Desojo JB, Pol D. 2014. Anatomy and phylogenetic position of Venaticosuchus rusconii Bonaparte, 1970 (Archosauria, Pseudosuchia), from the Ischigualasto Formation (Late Triassic), La Rioja, Argentina. Journal of Vertebrate Paleontology 34: 1342-1356.

Benton MJ. 2004. Origin and relationships of dinosauria. In: Weishampel DB, Dodson P, Osmólska H, eds. The Dinosauria, 2nd edn. Berkeley: University of California Press, 7-19.

Benton MJ, Clark JM. 1988. Archosaur phylogeny and the relationships of the Crocodylia. In: Benton MJ ed. The phylogeny and classification of the Tetrapods. Oxford: Clarendon Press, 295-338.

Benton MJ, Walker AD. 2002. Erpetosuchus, a crocodile-like basal archosaur from the Late Triassic of Elgin, Scotland. Zoological Journal of the Linnean Society 136: 25-47.

Bonaparte JF. 1972. Los tetrápodos del sector superior de la Formación Los Colorados, La Rioja, Argentina. (Triásico Superior) I Parte. Opera Lilloana XXII: 1-185.

Bonaparte JF. 1975a. Nuevos materiales de Lagosuchus talampayensis Romer (Thecodontia-Pseudosuchia) y su significado en el origen de los Saurischia. Chañarense inferior, Triásico medio de Argentina. Acta Geológica Lilloana 13: 5-90.

Bonaparte JF. 1975b. The family Ornithosuchidae (Archosauria: Thecodontia). Colloque international C.N.R.S. 218: 485-502.

Bremer K. 1994. Branch support and tree stability. Cladistics 10: $295-304$

Brinkman D. 1981. The origin of the crocodiloid tarsi and the interrelationships of the thecodontian archosaurs. Breviora 464: $1-23$.

Brochu CA. 1992. Ontogeny of the postcranium in crocodylomorph archosaurs. Unpublished MS Thesis, University of Texas at Austin, Texas.

Brochu CA. 1996. Closure of neurocentral sutures during crocodilian ontogeny: implications for maturity assessment in fossil archosaurs. Journal of Vertebrate Paleontology 16: 49-62.

Brusatte SL, Benton MJ, Desojo JB, Langer MC. 2010. The higher-level phylogeny of Archosauria (Tetrapoda: Diapsida). Journal of Systematic Palaeontology 8: 3-47.

Buffrénil V de. 1982. Morphogenesis of bone ornamentation in extant and extinct crocodilians. Zoomorphology 99: $155-166$.

Buffrénil V de, Clarac F, Fau M, Martin S, Pellé E, Laurin M. 2015. Differentiation and growth of bone ornamentation in vertebrates: a comparative histological study among the Crocodylomorpha. Journal of Morphology 276: $425-445$.
Butler R, Sullivan C, Ezcurra MD, Liu J, Lecuona A, Sookias RB. 2014. New clade of enigmatic early archosaurs yields insights into early pseudosuchian phylogeny and the biogeography of the archosaur radiation. BMC Evolutionary Biology 14: 128.

Chatterjee S. 1978. A primitive parasuchid (phytosaur) reptile from the Upper Triassic Maleri Formation of India. Palaeontology 21: 83-127.

Clark JM. 1994. Patterns of evolution in Mesozoic Crocodyliformes. In: Fraser NC, Sues H-D, eds. In the shadow of the dinosaurs. Early Mesozoic tetrapods. Cambridge: Cambridge University Press, 84-97.

Clark JM, Sues H-D. 2002. Two new basal crocodylomorph archosaurs from the Lower Jurassic and the monophyly of the Sphenosuchia. Zoological Journal of the Linnean Society 136: 77-95.

Clark JM, Sues H-D, Berman DS. 2000. A new specimen of Hesperosuchus agilis from the Upper Triassic of New Mexico and the interrelationships of basal crocodylomorph archosaurs. Journal of Vertebrate Paleontology 20: 683-704.

Clark JM, Xu X, Forster CA, Wang Y. 2004. A Middle Jurassic 'sphenosuchian' from China and the origin of the crocodylian skull. Nature 430: 1021-1024.

Crush PJ. 1984. A Late Upper Triassic sphenosuchid crocodilian from Wales. Palaeontology 27: 131-57.

Desojo JB, Arcucci AB. 2009. New material of Luperosuchus fractus (Archosauria: Crurotarsi) from the Middle Triassic of Argentina: the earliest known South American 'Rauisuchian'. Journal of Vertebrate Paleontology 29: 1311-1315.

Desojo JB, Ezcurra MD, Schultz CL. 2011. An unusual new archosauriform from the Middle-Late Triassic of southern Brazil and the monophyly of Doswelliidae. Zoological Journal of the Linnean Society 161: 839-871.

Dilkes DW, Sues H-D. 2009. Redescription and phylogenetic relationships of Doswellia kaltenbachi (Diapsida: Archosauriformes) from the Upper Triassic of Virginia. Journal of Vertebrate Paleontology 29: 58-79.

Donoghue MJ, Olmstead RG, Smith JF, Palmer JD. 1992. Phylogenetic relationships of Dipsacales based on $r b c L$ sequences. Annals of the Missouri Botanical Garden 79: 333-345.

Ewer RF. 1965. The anatomy of the thecodont reptile Euparkeria capensis Broom. Philosophical Transactions of the Royal Society, London, Series B 248: 379-435.

Ezcurra MD, Lecuona A, Martinelli A. 2010. A new basal archosauriform diapsid from the Lower Triassic of Argentina. Journal of Vertebrate Paleontology 30: 1433-1450.

Ezcurra MD, Trotteyn MJ, Fiorelli LE, von Baczko MB, Taborda JRA, Iberlucea M, Desojo JB. 2013. The oldest rhynchosaur from Argentina: a Middle Triassic rhynchosaurid from the Chañares Formation (Ischigualasto-Villa Unión Basin, La Rioja Province). Paläontologische Zeitschrift 88: 453-460.

Farris JS. 1989. The retention index and the rescaled consistency index. Cladistics 5: 417-419.

Farris JS, Albert VA, Källersjö M, Lipscomb D, Kluge AG. 1996. Parsimony jackknifing outperforms neighbor-joining. Cladistics 12: 99-124.

Felsenstein J. 1985. Confidence limits on phylogenies: an approach using the bootstrap. Evolution 39: 783-791. 
Fiorelli LE, Ezcurra MD, Hechenleitner EM, Argañaraz E, Taborda JRA, Trotteyn MJ, von Baczko MB, Desojo JB. 2013. The oldest known communal latrines provide evidence of gregarism in Triassic megaherbivores. Scientific Reports 3: 3348 .

Goloboff P, Farris SJ, Källersjo M, Oxelman B, Ramírez MJ, Szumik CA. 2003. Improvements to resampling measures of group support. Cladistics 19: 324-332.

Goloboff PA, Farris JS, Nixon KC. 2008a. TNT: Tree analysis using new technologies. Program and documentation available from the authors and at http://www.zmuc.dk/ public/phylogeny

Goloboff PA, Farris JS, Nixon KC. 2008b. TNT, a free program for phylogenetic analysis. Cladistics 24: 774-786.

Gower DG, Schoch RR. 2009. Postcranial anatomy of the Rauisuchian Archosaur Batrachotomus kupferzellensis. Journal of Vertebrate Paleontology 29: 103-122.

Irmis R. 2007. Axial skeleton ontogeny in the Parasuchia (Archosauria: Pseudosuchia) and its implications for ontogenetic determination in archosaurs. Journal of Vertebrate Paleontology 27: 350-361.

Irmis R, Mundil R, Marsicano C, Mancuso A. 2013. U-Pb dating of redeposited volcanics in non-marine sedimentary strata: case studies from the Early Mesozoic. Journal of Vertebrate Paleontology, Program and Abstracts 2013: 147.

Juul L. 1994. The phylogeny of basal archosaurs. Palaeontologia Africana 31: 1-38.

Källersjö M, Farris JS, Kluge AG, Bult C. 1992. Skewness and permutation. Cladistics 8: 275-287.

Kearney M. 2002. Fragmentary taxa, missing data, and ambiguity: mistaken assumptions and conclusions. Systematic Biology 51: 369-381.

Kitching IJ, Forey PL, Humphries CJ, Williams DM. 1998. Cladistics. The theory and practice of parsimony analysis. Oxford: Oxford University Press.

Kluge AG, Farris JS. 1969. Quantitative phyletics and the evolution of anurans. Systematic Zoology 18: 1-32.

Krebs B. 1965. Ticinosuchus ferox n. g. n. sp. Ein neuer Pseudosuchier aus der Trias des Monte San Giorgio. Schweizerische Paläontologische Abhandlungen 81: 1-140.

Lanyon SM. 1985. Molecular perspective on higher-level relationships in the Tyrannoidea (Aves). Systematic Zoology 34: 404-418.

Lautenschlager S, Desojo JB. 2011. Reassessment of the Middle Triassic rauisuchian archosaurs Ticinosuchus ferox and Stagonosuchus nyassicus. Paläontologische Zeitschrift 85: 357-381

Lecuona A. 2007. Osteología y musculatura del miembro posterior de Gracilisuchus stipanicicorum Romer, 1972 (Amniota: Crurotarsi). Unpublished Thesis, University of Buenos Aires, Buenos Aires.

Lecuona A. 2013. Anatomía y relaciones filogenéticas de Gracilisuchus stipanicicorum y sus implicancias en el origen de Crocodylomorpha. Unpublished Ph.D. Thesis, University of Buenos Aires, Buenos Aires. Available at: http://digital. bl.fcen.uba.ar/Download/Tesis/Tesis_5266_Lecuona.pdf

Lecuona A, Desojo JB. 2011. Hind limb osteology of Gracilisuchus stipanicicorum (Archosauria: Pseudosuchia). Earth and Environmental Science Transactions of the Royal Society of Edinburgh 102: 105-128.
Li C, Wu XC, Cheng YN, Sato T, Wang L. 2006. An unusual archosaurian from the marine Triassic of China. Die Naturwissenschaften 93: 200-206.

Long RA, Murry PA. 1995. Late Triassic (Carnian and Norian) tetrapods from the southwestern United States. Bulletin of the New Mexico Museum of Natural History \& Science 4: 1-254.

Marsicano CA, Irmis RB, Mancuso AC, Mundil R, Chemale F. 2016. The precise temporal calibration of dinosaur origin. Proceedings of the National Academy of Sciences of the USA 113: 509-513.

Mook CC. 1921. Notes on the postcranial skeleton in the Crocodilia. Bulletin of American Museum of Natural History 44: 67-100.

Nesbitt SJ. 2005. Osteology of the Middle Triassic pseudosuchian archosaur Arizonasaurus babbitti. Historical Biology 17: 19-47.

Nesbitt SJ. 2011. The early evolution of Archosaurs: relationships and the origin of major clades. Bulletin of American Museum of Natural History 352: 1-292.

Nesbitt SJ, Butler RJ. 2012. Redescription of the archosaur Parringtonia gracilis from the Middle Triassic Manda beds of Tanzania, and the antiquity of Erpetosuchidae. Geological Magazine 150: 225-238

Nesbitt SJ, Sidor CA, Irmis RB, Angielczyk KD, Smith RM, Tsuji LA. 2010. Ecologically distinct dinosaurian sister group shows early diversification of Ornithodira. Nature 464: 95-98.

Nesbitt SJ, Sidor CA, Angielczyk KD, Smith RMH, Tsuji LA. 2014. A new archosaur from the Manda beds (Anisian, Middle Triassic) of southern Tanzania and its implications for character state optimizations at Archosauria and Pseudosuchia. Journal of Vertebrate Paleontology 34: 1357-1382.

Nixon KC, Wheeler QD. 1992. Extinction and the origin of species. In: Novacek MJ, Wheeler QD, eds. Extinction and phylogeny. New York: Columbia University Press, 119-143.

Novas FE, Salgado L, Suárez M, Agnolín FL, Ezcurra MD, Chimento NR, de la Cruz R, Isasi MP, Vargas AO, Rubilar-Rogers D. 2015. An enigmatic plant-eating theropod from the Late Jurassic period of Chile. Nature 522: 331-334.

Olsen PE, Sues H-D, Norell MA. 2000. First record of Erpetosuchus (Reptilia: Archosauria) from the late Triassic of North America. Journal of Vertebrate Paleontology 20: 633-636.

Parrish JM. 1991. A new specimen of an early crocodylomorph (cf. Sphenosuchus sp.) from the Upper Triassic Chinle Formation of Petrified Forest National Park, Arizona. Journal of Vertebrate Paleontology 11: 198-212.

Parrish JM. 1993. Phylogeny of the Crocodylotarsi, with reference to archosaurian and crurotarsan monophyly. Journal of Vertebrate Paleontology 13: 287-308.

Peyer K, Carter JG, Sues H-D, Novak SE, Olsen PE. 2008. A new suchian archosaur from the Upper Triassic of North Carolina. Journal of Vertebrate Paleontology 28: 363-381.

Pol D. 2003. New remains of Sphagesaurus huenei (Crocodylomorpha: Mesoeucrocodylia) from the Late Cretaceous of Brazil. Journal of Vertebrate Paleontology 23: 817-831.

Pol D. 2005. Postcranial remains of Notosuchus terrestris Woodward (Archosauria: Crocodyliformes) from the Upper Cretaceous of Patagonia, Argentina. Ameghiniana 42: 21-38.

Pol D, Gasparini Z. 2009. Skull anatomy of Dakosaurus andiniensis (Thalattosuchia: Crocodylomorpha) and 
the phylogenetic position of Thalattosuchia. Journal of Systematic Palaeontology 7: 163-197.

Pol D, Leardi JM, Lecuona A, Krause M. 2012. Postcranial anatomy of Sebecus icaeorhinus (Crocodyliformes, Sebecidae) from the Eocene of Patagonia. Journal of Vertebrate Paleontology 32: 328-354.

Rieppel O. 1993. Patterns of diversity in the reptilian skull. In: Hanken J, Hall BK, eds. The skull, Volume 2: patterns of structural and systematic diversity. Chicago: University of Chicago Press, 344-390.

Rogers RR, Swisher CCI, Sereno PC, Monetta AM, Forster CA, Martínez RN. 1993. The Ischigualasto tetrapod assemblage (Late Triassic, Argentina) and ${ }^{40} \mathrm{Ar} /{ }^{39} \mathrm{Ar}$ dating of dinosaur origins. Science 260: 794-797.

Rogers RR, Arcucci AB, Abdala F, Sereno PC, Forster CA, May CL. 2001. Paleoenvironment and taphonomy of the Chañares Formation tetrapod assemblage (Middle Triassic), Northwestern Argentina: spectacular preservation in volcanogenic concretions. Palaios 16: 461-481.

Romer AS. 1966. The Chañares (Argentina) Triassic reptile fauna. I. Introduction. Breviora 247: 1-14.

Romer AS. 1967. Collecting Triassic fossils in argentina: or, how we put the romance back in fossil-hunting. Harvard Alumni Bulletin, 1-6.

Romer AS. 1971a. The Chañares (Argentina) Triassic reptile fauna. VIII. A fragmentary skull of a large thecodont, Luperosuchus fractus. Breviora 373: 1-8.

Romer AS. 1971b. The Chañares (Argentina) Triassic reptile fauna. X. Two new but incompletely known long-limbed pseudosuchians. Breviora 378: 1-10.

Romer AS. 1972a. The Chañares (Argentina) Triassic reptile fauna. XIII. An early ornithosuchid pseudosuchian, Gracilisuchus stipanicicorum, gen. et sp. nov. Breviora 389: 1-24.

Romer AS. 1972b. The Chañares (Argentina) Triassic reptile fauna. XIV. Lewisuchus admixtus gen. et sp. nov., a further thecodont from the Chañares beds. Breviora 390: 1-13.

Romer AS, Jensen JA. 1966. The Chañares (Argentina) Triassic reptile fauna. II. Sketch of the geology Río Chañares - Río Gualo Region. Breviora 252: 1-20.

Schoch RR 2007. Osteology of the small archosaur Aetosaurus from the Upper Triassic of Germany. Neues Jahrbuch für Geologie und Paläontologie, Abhandlungen 246: 1-35.

Schuh RT, Polhemus JT. 1980. Analysis of taxonomic congruence among morphological, ecological, and biogeographic data sets for the Leptopodomorpha (Hemiptera). Systematic Zoology 29: 1-26.

Sereno PC. 1991. Basal archosaurs: phylogenetic relationships and functional implications. Memoir (Society of Vertebrate Paleontology) 2: 1-53.

Sereno PC, Arcucci AB. 1990. The monophyly of the crurotarsal archosaur and the origin of birds and crocodyle ankle joints. Neues Jahrbuch für Geologie und Paläontologie, Abhandlungen 180: 21-52.

Sereno PC, Arcucci AB. 1993. Dinosaurian precursors from the Middle Triassic of Argentina: Lagerpeton chanarensis. Journal of Vertebrate Paleontology 13: 385-399.
Sereno PC, Arcucci AB. 1994. Dinosuarian precursors from the Middle Triassic of Argentina: Marasuchus lilloensis, gen. nov. Journal of Vertebrate Paleontology 14: 53-73.

Sereno PC, Wild R. 1992. Procompsognathus: theropod, 'thecodont' or both? Journal of Vertebrate Paleontology 12: 435-458.

Sokal RR, Rohlf FJ. 1981. Taxonomic congruence in the Leptopodomorpha re-examined. Systematic Zoology 30: 309-325.

Sookias RB, Sullivan C, Liu J, Butler RJ. 2014. Systematics of putative euparkeriids (Diapsida: Archosauriformes) from the Triassic of China. PeerJ 2: e658.

Stipanicic PN. 1983. The Triassic of Argentina and Chile. In: Moullade M, Nairm AEM, eds. The Phanerozoic geology of the world. Amsterdam: Elsevier Press, 181-199.

Sues H-D, Olsen PE, Carter JG, Scott DM. 2003. A new crocodylomorph archosaur from the Upper Triassic of North Carolina. Journal of Vertebrate Paleontology 23: 329-343.

Trotteyn MJ, Ezcurra MD, von Baczko MB, Desojo JB. 2014. On the presence of the genus Rhadinosuchus in the Late Middle-Early Late Triassic Chañares Formation of Northwestern Argentina. In: Abstract book of 4th International Palaeontological Congress, Mendoza, Argentina, September $28^{\text {th }}-$ October $3^{\text {rd }}, 2014$.

Tukey J. 1958. Bias and confidence in not quite large samples (abstract). The Annals of Mathematical Statistics 29: 614.

Walker AD. 1961. Triassic reptiles from the Elgin area: Stagonolepis, Dasygnathus and their allies. Philosophical Transactions of the Royal Society, London. Series B, Biological Sciences 244: 103-204.

Walker AD. 1964. Triassic reptiles from the Elgin Area: Ornithosuchus and the origin of Carnosaurs. Philosophical Transactions of the Royal Society of London. Series B, Biological Sciences 248: 53-134.

Weinbaum JC. 2013. Postcranial skeleton of Postosuchus kirkpatricki (Archosauria: Paracrocodylomorpha), from the upper Triassic of the United States. In: Nesbitt SJ, Desojo JB, Irmis RB, eds. Anatomy, phylogeny and palaeobiology of early archosaurs and their kin. London: Geological Society, London, Special Publications, 525-553.

Wu X-C, Chatterjee S. 1993. Dibothrosuchus elaphros, a crocodylomorph from the Lower Jurassic of China and the phylogeny of the sphenosuchian. Journal of Vertebrate Paleontology 13: 58-89.

Wu X-C, Russell AP. 2001. Redescription of Turfanosuchus dabanensis (Archosauriformes) and new information on its phylogenetic relationships. Journal of Vertebrate Paleontology 21: 40-50.

Wu X-C, Liu J, Li J-L. 2001. The anatomy of the first archosauriform (Diapsida) from the terrestrial Upper Triassic of China. Vertebrata PalAsiatica 39: 251-265.

Young CC. [Zang Z.]. 1973. On a new pseudosuchian from Turfan, Sinkiang. Memoirs of the Institute of Vertebrate Palaeontology and Paleoanthropology Academia Sinica 10: 15-38. 


\section{SUPPORTING INFORMATION}

Additional Supporting Information may be found in the online version of this article at the publisher's website:

Appendix I. Character list and discussion of characters 412-482.

Appendix II. List of taxa and specimens.

Appendix III. Taxon scorings.

Appendix IV. References for the Supporting Information.

Appendix V. Tables of measurements and phylogenetic analysis.

Appendix VI. Supplementary Figures S1-S11. 